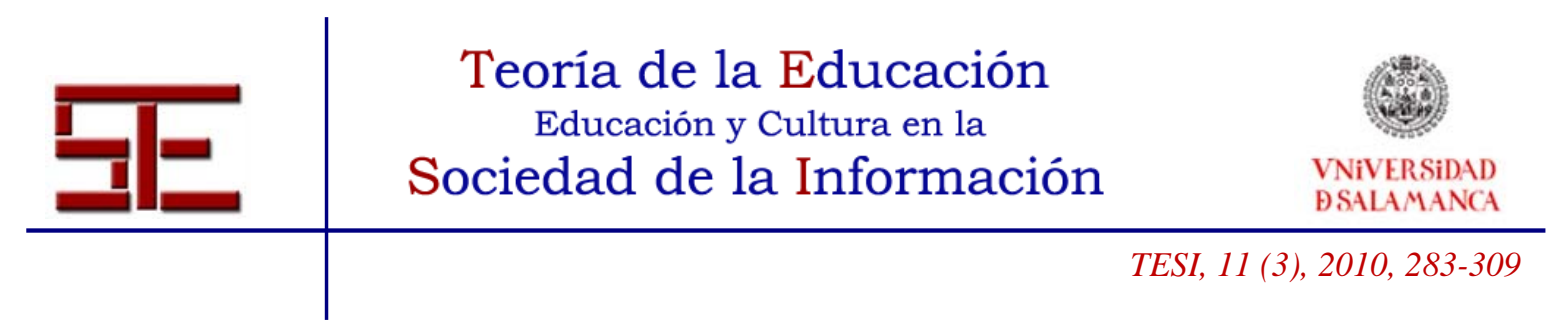

\title{
ANÁLISIS DE “BUENAS PRÁCTICAS” DEL E-LEARNING EN LAS UNIVERSIDADES ANDALUZAS. (1)
}

\section{Resumen:}

Este artículo ofrece los resultados obtenidos del analisis de "buenas prácticas" de treinta profesores de las diferentes Universidades Andaluzas. Para la recogida de datos se han utilizado tres instrumentos: biograma, entrevistas individualizadas y observación de materiales. Estos profesores tienen una actitud positiva hacia la formación e-learning, trabajan en grupo y llevan más de 2 años impartiéndolas junto a la presencial. Consideran esta formación como una gran ayuda para los alumnos por el volumen de material disponible, la flexibilización en su uso, la posibilidad de consulta y el trato es más personal. Por otro lado, estos profesores señalan la cantidad de tiempo y esfuerzo que requiere la elaboración y actualización de los materiales. Así como la escasa formación para su utilización didáctica y educativa, subsanada por su autoformación. Los materiales utilizados son considerados como buenos en lo técnico, didáctico y comunicativo.

Palabras clave: e-learning, buenas prácticas, enseñanza superior, formación profesorado, materiales e-learning.

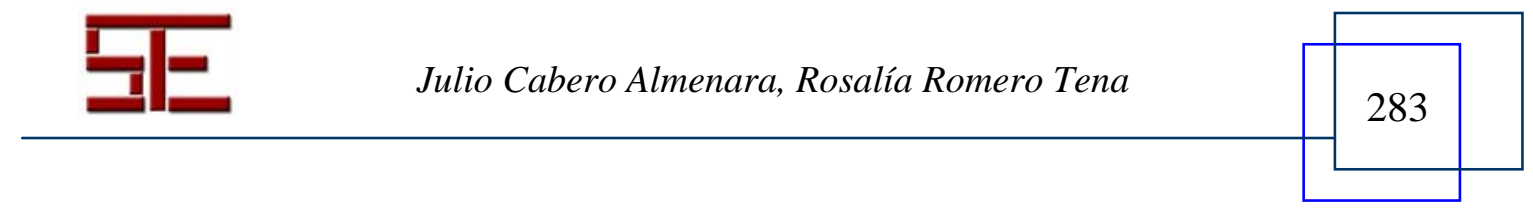




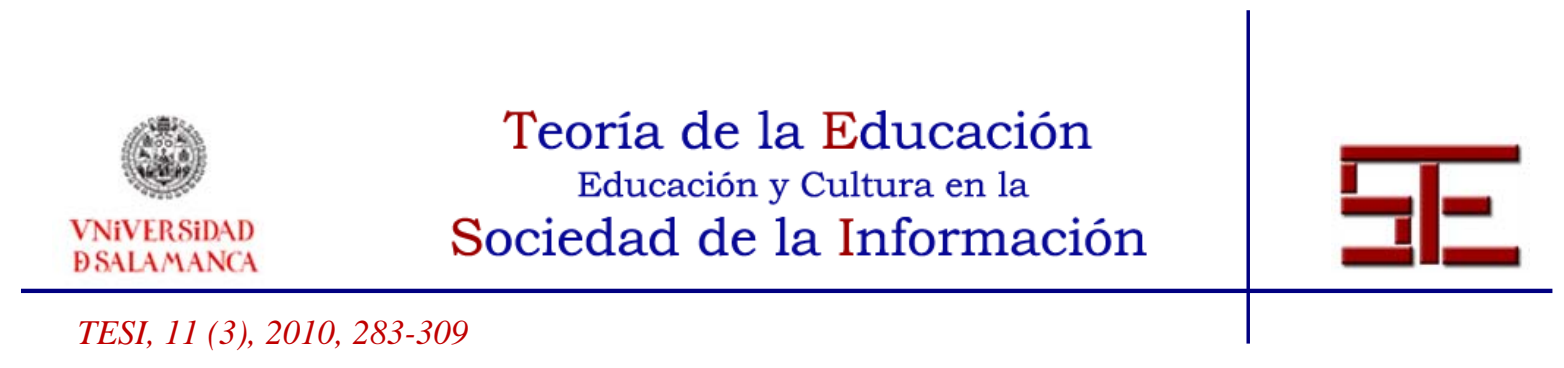

\title{
ANALYSIS OF "BEST PRACTICES" OF E-LEARNING IN ANDALUSIAN UNIVERSITIES. (1)
}

\begin{abstract}
:
This article provides the results of the analysis of "best practices" of thirty teachers of different Andalusian Universities. For the collection of data we have been used three instruments: biogram, individualized interviews and observation of materials. These teachers have a positive attitude towards e-learning, working in groups and carry more than 2 years teaching with (together) the face to face. They consider this training as a high help to students because of the high volume of available material, application flexibility, the possibility of consultation and the treatment is more personal. Moreover, these teachers pointed out the amount of time and effort required for the preparation and updating of materials, and also here poor training for teaching and educational use, that is remedied by themselves. The materials used are is adecuated in the technical, teaching and in the communication way.
\end{abstract}

Keywords: e-learning, best practices, higher education, teacher training, e-learning materials.

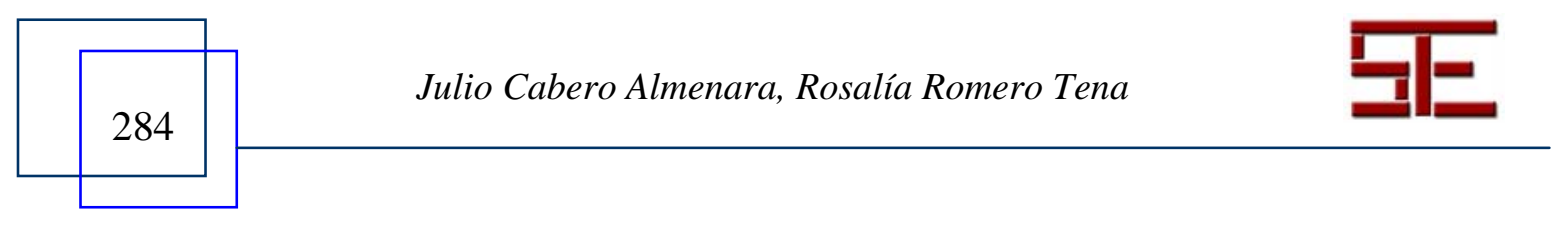




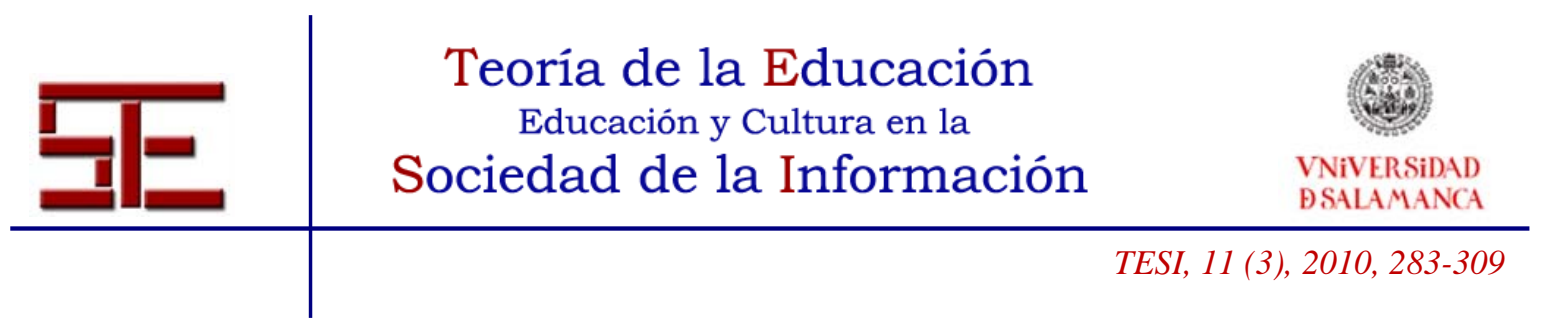

\section{ANÁLISIS DE "BUENAS PRÁCTICAS" DEL E-LEARNING EN LAS UNIVERSIDADES ANDALUZAS.(1)}

Fecha de recepción: 03/01/2009; fecha de aceptación: 25/01/2009; fecha de publicación: 28/02/10

Julio Cabero Almenara

cabero@us.es

Universidad de Sevilla.

Rosalía Romero Tena

rromero@us.es

Universidad de Sevilla.

\section{1.- EL E-LEARNING DESDE LA INVESTIGACIÓN EDUCATIVA.}

En los últimos tiempos los estudios de "buenas prácticas" se están convirtiendo en un hecho para que las organizaciones, instituciones y personas aprendan, no mediante las soluciones y sugerencias emitidas por expertos, sino mediante el análisis y la reflexión de las actividades realizadas directamente por otros, que consideramos exitosas. En nuestro caso podríamos decir que las "buenas prácticas" son las intervenciones educativas de los profesores y las instituciones educativas que facilitan el desarrollo de actividades que permiten que los estudiantes alcancen los objetivos, y las capacidades y competencias establecidas. Además, deben poseer otra característica y es que sean reconocidas por los demás. En esta línea un estudio que está adquiriendo significación en los últimos tiempos es el trabajo realizado por Bain (2006) sobre lo que hacen los mejores profesores universitarios.

Desde nuestro punto de vista la investigación en e-learning se ha ido desplazando desde la preocupación por los elementos técnicos y el tipo de plataforma a utilizar, al análisis de otras problemáticas más útiles para su incorporación al terreno educativo. Como señalan Planella y Rodríguez (2004), dentro de la investigación en e-learning, podemos diferenciar distintos enfoques: los preocupados por la tecnología y por los procesos instruccionales, y los centrados en las interacciones sociales del e-learning y las transformaciones sociales que se producen con el mismo. A estos les incorporaríamos algunas variables más como las preocupadas por los aspectos organizativos, a las

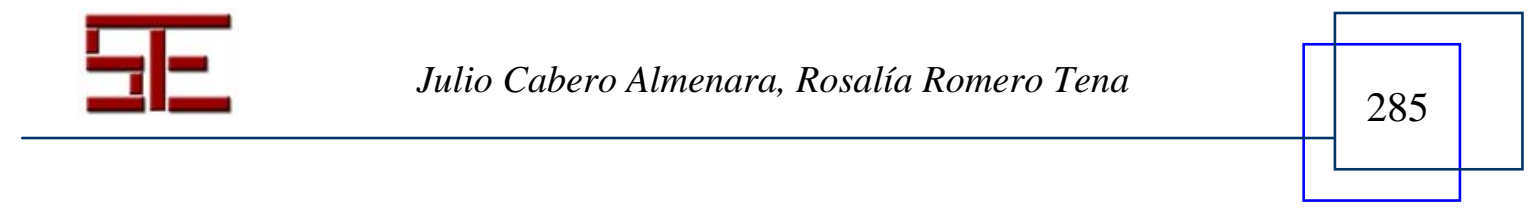




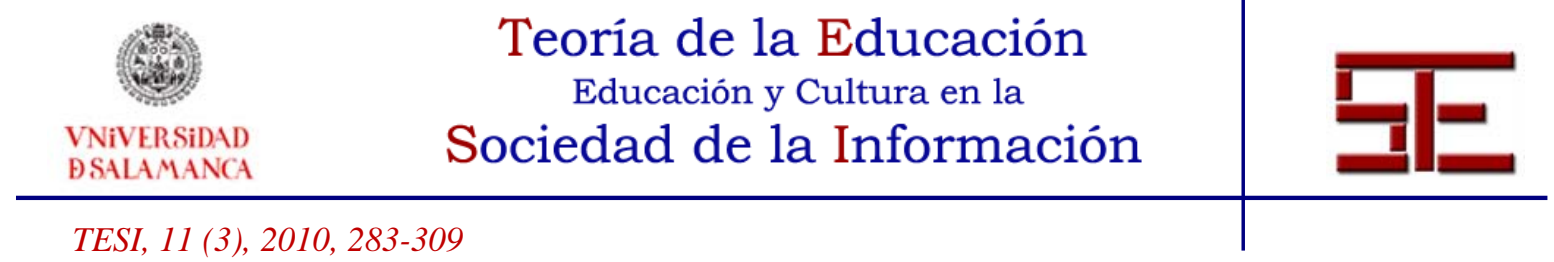

centradas en la influencia de los estilos de aprendizaje de los estudiantes en el tipo de interacción que establecen con los mismos, o sus repercusiones cognitivas, etc.

En esta línea sirva de ejemplo la iniciativa de la Dirección General de Educación y Cultura de la Comisión Europea que encargó a la empresa PLS Ramboll (2004) un estudio para analizar la incorporación del e-learning a las Universidades Europeas. Los resultados ofrecen recomendaciones para las futuras investigaciones tales como: realizar preguntas de orden pedagógica y didáctica; trabajar la interacción didáctica entre los estudiantes y sus profesores; plantear investigaciones de orden de organizacional ligadas a las TICs y al e-learning a los niveles de formación superior; la gestión de la innovación; la durabilidad de las soluciones; estudios de costo y ganancia sobre las TICs y el aprendizaje virtual; modificación de las normas de examen y de evaluación como consecuencia de aplicación de las TICs; si el contexto físico constituye un obstáculo para la aplicación intensiva de las TICs sobre el campus universitario; desarrollar nuevos métodos de evaluación y de estimación de la calidad del e-learning; modificar la cultura y las actitudes de los profesores; cuestiones de género; y cuestiones ligadas a la puesta en escena.

En general, podemos decir que las temáticas sobre las que se han realizado las investigaciones en el terreno del e-learning, han sido muy diversas. Algunas se han dirigido hacia sus repercusiones en los aspectos de tipo económico en lo que se refiere a la relación de coste-beneficio de su puesta en acción respecto a otro tipo de metodologías, fundamentalmente la presencial y contemplando diferentes tipos de costos: de capital, recurrentes, de distribución, variables, y fijos (Gargallo, y otros, 2003). Otras se han centrado en la problemática del género y si ello repercutía en la preferencia por parte de los estudiantes por este tipo de metodologías, así como por el tipo de nivel que realizaban dentro de la misma (Duart y otros, 2008). Y otras se han centrado en analizar el nivel de satisfacción mostrado tanto por los estudiantes como por los profesores al participar en estas experiencias formativas (Llorente y Cabero, 2008; Cabero, 2010).

En cuanto a las que se refieren al rendimiento alcanzado por los estudiantes, existe un grupo de investigaciones realizadas a través de estudios comparativos. Estas se han preocupado por conocer si se aprendía más, menos o igual con acciones formativas soportadas en redes telemáticas en comparación con la formación de tipo presencial. Podemos decir que las investigaciones sobre aprendizaje basado en red han puesto de manifiesto que no hay diferencias significativas en el rendimiento entre los estudiantes que han seguido una metodología tradicional y aquellos que han cursado la enseñanza basada en tecnología.

En esta línea recientemente se ha publicado un metaanálisis efectuado por el Departamento de Educación de EE.UU. (Means y otros, 2009) que recogía los resultados de una investigación sistemática llevada a cabo en niveles no universitarios desde 1996 a 2008. En este trabajo se identifican 51 efectos diferentes que pueden ser

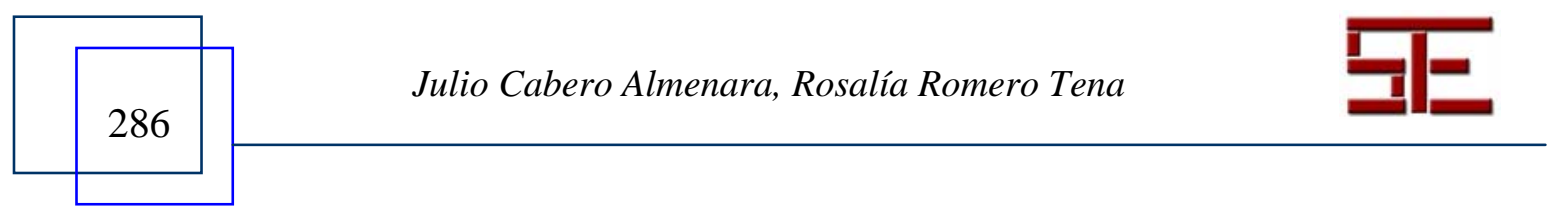




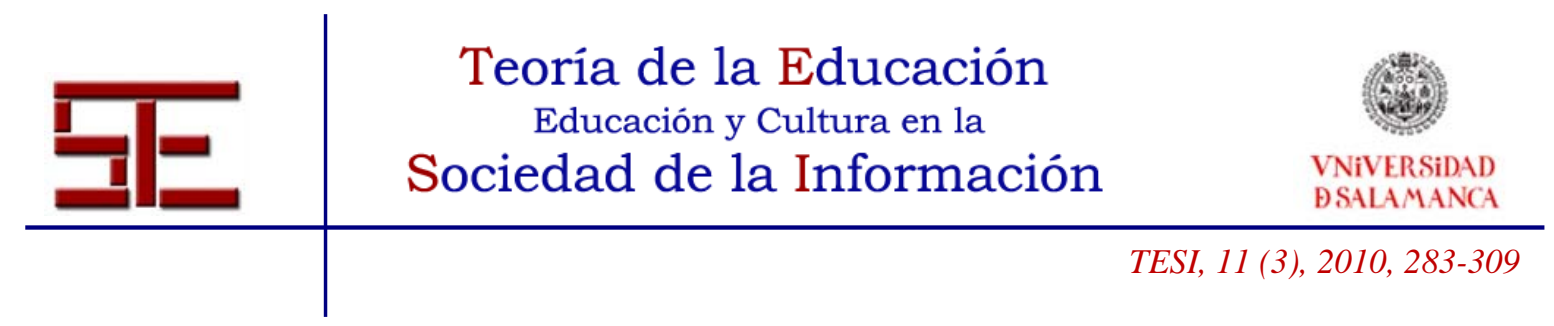

objetos de un metaanálisis, y como gran resultado del mismo se nos señala que como promedio los estudiantes de la formación on-line obtienen mejores resultados que los que reciben una instrucción presencial. Cuatro fueron las preguntas que dirigían el trabajo: ¿Cómo de efectiva es la formación on-line comparada con la instrucción cara a cara?; ¿El complemento de la formación on-line con la instrucción cara a cara enfatiza el aprendizaje?; ¿Qué prácticas están asociadas con una más efectiva formación online?; y ¿Qué condiciones influencian la efectividad del aprendizaje on-line?

Los hallazgos principales los podemos sintetizar en los siguientes: se han realizado pocos estudios sistemáticos y rigurosos sobre la efectividad de aprendizaje on-line con estudiantes del nivel K-12; los estudiantes que desarrollan las clases de forma on-line ejecutan por promedio mejor que los que lo hacen de tradicional cara a cara; la instrucción que combina la formación on-line con la cara a cara da mejor resultados que aquellas dos por separado; los estudiantes de la formación en condiciones on-line pasan más tiempo realizando tareas y ello tiene repercusiones beneficiosas para alcanzar resultados de aprendizaje significativos; muchas de las variaciones en las formas en las cuales diferentes estudios implementan el aprendizaje on-line afecta a los productos que los estudiantes adquieren de forma significativa; la efectividad de los enfoques del aprendizaje on-line se relaciona de forma amplia con los contenidos y tipos de estudiantes; y el tamaño de los efectos es más grande en los estudios en los cuales las condiciones de formación on-line y presencial varían en términos de materiales curriculares y aspectos de la aproximación instruccional además de los medios de instrucción.

También quisiéramos hacer referencia a un grupo de investigaciones que se han centrado en analizar las posibilidades que tiene un tipo de diseño de materiales educativos utilizados en red. En concreto, el que viene determinado por la ubicación de objetivos, mapa conceptual, presentación, desarrollo de los contenidos de forma atractiva e hipertextual, utilización diversidad de elementos simbólicos y multimedia, calidad científica y conceptual, utilización de una diversidad de e-actividades y la incorporación de recursos de extensión. Respecto a la adquisición de información por parte de los estudiantes o el aumento de su nivel de satisfacción de participación en la experiencia (Cabero, 2004; Llorente y Cabero, 2008).

Y por último, comentar los estudios que se han potenciado últimamente como es el de los metanálisis sobre investigaciones realizadas sobre la temática del e-learning. Y este aspecto nos encontramos con el trabajo de Tallent-Runnels y otros (2006), o el realizado por Cabero y otros (2008), en este último perseguíamos realizar un metaanálisis de aquellas investigaciones que en los últimos 10 años se habían referido al análisis de la problemática de los efectos sobre el rendimiento y otras variables de acciones formativas e-learning aplicadas en contextos de formación universitaria: Este estudio nos permitió identificar los instrumentos, metodologías y problemáticas más utilizadas en temáticas referidas a: "Entornos de aprendizaje de e-learning, plataformas de

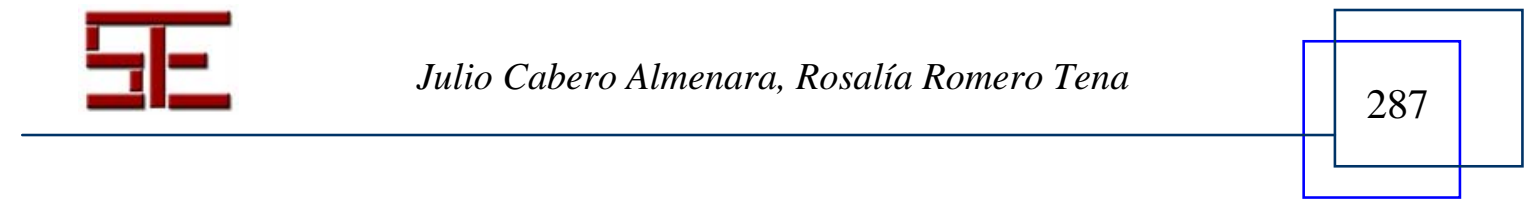




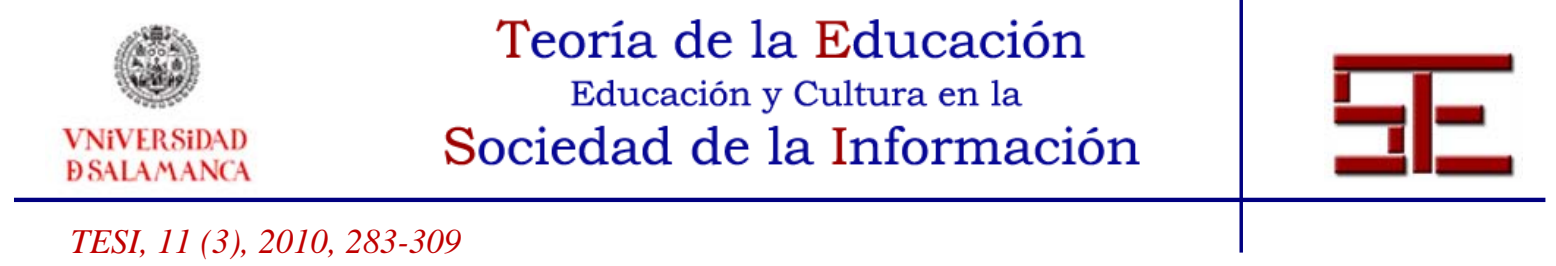

teleformación", "Diseño de materiales y/u objetos digitales utilizados en acciones de elearning”, "Estrategias y metodologías didácticas utilizadas en las acciones de elearning" o "Cómo los estudiantes suelen tener una actitud favorable y un rendimiento positivo", etc...

En síntesis, podemos decir que en la actualidad se están configurando sobre el ámbito de la formación en red diferentes líneas y preocupaciones: a) el diseño de las características de los materiales educativos, b) la comunicación en estos entornos, c) el grado de satisfacción de los estudiantes que participan en estas acciones formativas, d) la tutoría virtual, e) el trabajo colaborativo en estos entornos, f) la influencia de los estilos cognitivos, de enseñanza y de aprendizaje, g) las funciones y roles del profesorado; el diseño de objetos y repositorios de aprendizaje, h) las diferencias y semejanzas entre acciones "e-learning” y "b-learning”, i) o la construcción de entornos personales de aprendizaje (Tejada, 2007; Baelo, 2009; Castañeda, y Sánchez, 2009; Blázquez y Alonso, 2009). Sin lugar a dudas, estos trabajos nos están ofreciendo pistas para la puesta en acción de esta modalidad formativa.

\section{2.- NUESTRO ESTUDIO.}

Con nuestra investigación se pretende llevar a cabo un estudio de buenas prácticas, siguiendo la modalidad de estudio de casos (Arnal y otros, 1992; Stake, 1998; Pérez Serrano, 1994), y más concretamente de casos múltiples. Estudio de casos, que como señala Pérez Serrano (1994) podemos definirlo “... como una metodología de análisis grupal, cuyo aspecto cualitativo nos permite extraer conclusiones de fenómenos reales o simulados en una línea formativa-experimental, de investigación y/o desarrollo de la personalidad humana o de cualquier otra realidad individualizada o única”. (Pérez Serrano, 1994, 83)

En ella pretendíamos alcanzar diferentes objetivos: a) identificar los usos que hace el profesorado de las Universidades Andaluzas del e-learning, b) conocer los problemas técnicos, didácticos y organizativos más destacados con que se encuentran para la incorporación del e-learning, y c) ver las características que presentan los materiales didácticos utilizados en su práctica de la enseñanza.

Su puesta en marcha supuso una serie de etapas y fases. La inicial comienza cuando el investigador realiza una serie de acciones que van desde la toma de contacto con el objeto de estudio a la construcción o determinación de los instrumentos que se utilizaran para la recogida de la información así como la concreción de los criterios que se utilizarán para la selección y la identificación de los mismos.

En este estudio uno de los aspectos más significativos es el de la selección. Los criterios que contemplamos para la validez de los casos fueron: a) la representatividad, b) la adecuación a los objetivos que se persiguen en la investigación, c) el tiempo del que

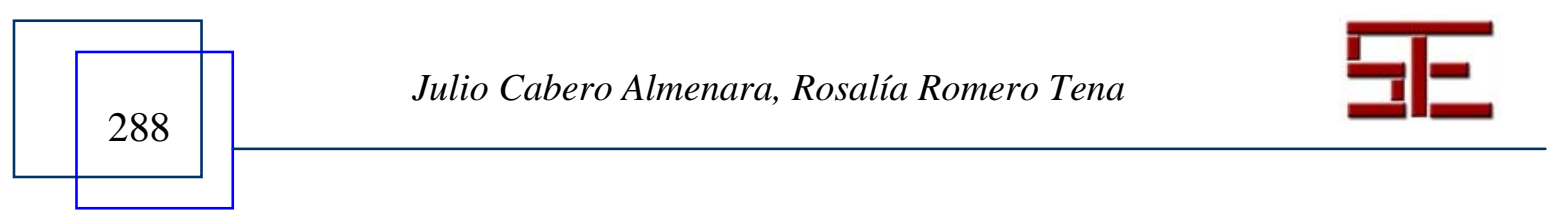




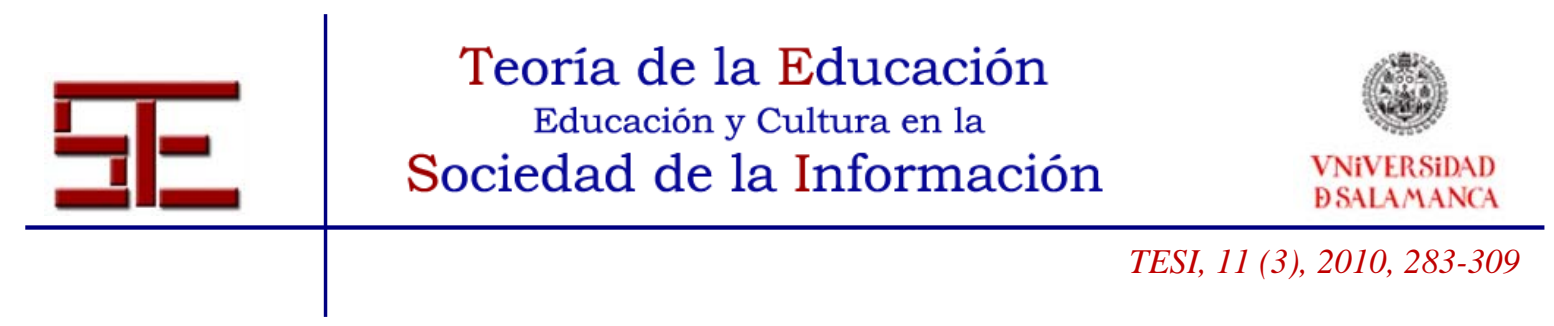

disponemos para realizar el estudio, e) y por supuesto el deseo de colaborar por parte de los implicados.

Una característica básica de la selección fue que los sujetos objeto de estudio fueron indicados directamente por los responsables de la implantación del "e-learning” en las diferentes Universidades Andaluzas. A ellos se les solicitó un grupo de tres profesores que fueran exitosos en la aplicación del e-learning con sus estudiantes, que tuvieran al menos un año de experiencia en este tipo de formación y que fueran reconocidos como de "buenas prácticas" por sus compañeros.

Las estrategias que utilizamos para recoger la información fueron cuatro: a) biograma del profesor o grupo de profesores que imparten la asignatura para su contextualización; b) entrevista en profundidad de forma individual al profesor o al grupo de profesores que desarrollaban la experiencia; c) análisis de los materiales producidos; y d) entrevista a grupos de alumnos. Señalar que por cuestión de espacio en este artículo, sólo nos centraremos en los datos referidos a los profesores, la visión de los alumnos puede observarse en la memoria de investigación (Cabero, 2010).

Con el biograma pretendíamos recoger información sobre aspectos como: asignatura/s impartida/s e impartida/s en red, número de profesores, número de años que lleva en la docencia universitaria, número de años que lleva realizando formación en red, categoría administrativa,...

De acuerdo a Cohen y Manion (1990) la entrevista puede utilizarse para fines diversos para recoger información relativa a los objetivos de la investigación; para conocer valores, preferencias, conocimientos, actitudes, creencias, etc., de los entrevistados, como recurso explicativo para ayudar a identificar variables y relaciones o para poder probar hipótesis o sugerir otras nuevas, y en conjunción con otros métodos para llevar a cabo una investigación. En nuestro caso lo utilizamos para recoger información directa de nuestros actores respecto a una serie de aspectos como: ¿Cuáles fueron los motivos que le llevaron a impartir docencia en la modalidad virtual (e-learning)?; ¿Qué aspectos positivos y negativos cree que tiene la modalidad de formación virtual tanto para los alumnos, como para los profesores?, ¿Qué competencias cree que deben tener los profesores y los alumnos para impartir y recibir docencia virtual universitaria?, o ¿Qué esfuerzos y medidas cree que debe adoptar la institución universitaria para facilitar la incorporación de esta modalidad de formación?

Estas entrevistas se realización en su gran mayoría personalmente (bien presencial o de forma telefónica) concertando con los docentes una cita para su realización por miembros del equipo de investigación con experiencia. Tan sólo en un par de casos se hizo vía correo electrónico tras facilitarles el protocolo de las preguntas que se le iban a formular; en estos casos fueron los profesores los que solicitaron realizarla de esta forma y los motivos que aludieron fueron de agenda. Al final de las mismas se les

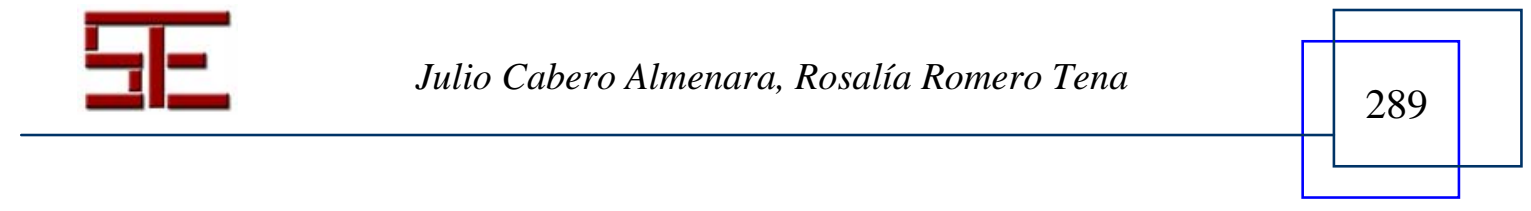




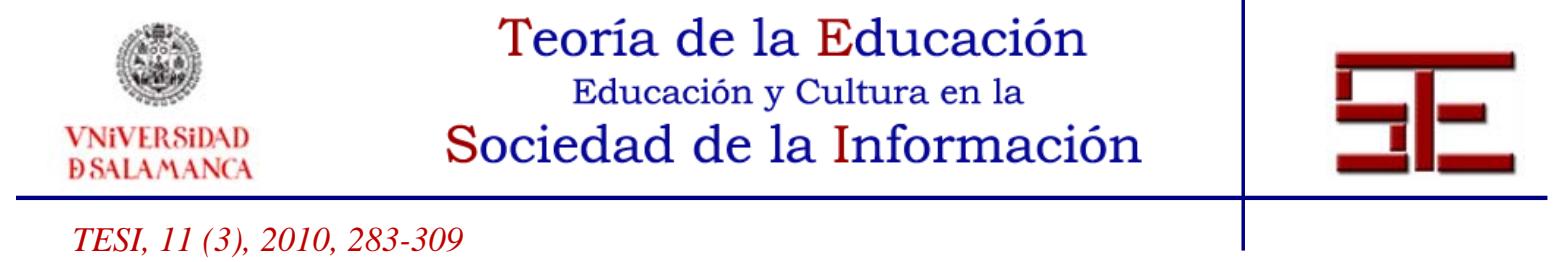

recordaba que necesitábamos que nos cumplimentaran el biograma y que nos facilitaran el acceso a sus asignaturas para poder realizar la ficha de observación de los materiales.

Para su análisis aplicamos el análisis de contenido, mediante el programa HiperResearch de Hess-Biber (1994), teniendo en cuenta en su aplicación las siguientes fases: pre análisis, formación del sistema de categorías, y codificación y análisis. Para la configuración del sistema de categorías se tuvieron en cuenta las propuestas de diferentes autores (Pérez Serrano, 1984; Bardin, 1986; y Clemente y Santaella, 1991), para crear un sistema que fuera exclusivo, homogéneo, pertinente, productivo y fiable.

Para la observación de los materiales que utilizan en su asignatura en e-learning se creó una ficha de observación y evaluación creada "ad hoc" para la investigación, que perseguía recoger información sobre el diseño tecnológico, pedagógico y comunicativo. Dentro del diseño tecnológico se evaluaron aspectos como: si se explican los navegadores que pueden ser puestos a disposición de los estudiantes; si se aportan los elementos técnicos correctos que el estudiante debe tener para poder seguir el curso: velocidad de conexión, plugings instalados, requisitos mínimos que debe tener el ordenador instalado, programas que deben estar dispuestos para los estudiantes,..; o si se especifican las competencias mínimas tecnológicas que debe tener el estudiante para poder desenvolverse con claridad en la acción formativa: manejo de la plataforma y competencia para la instalación de software. Por lo que se refiere al diseño pedagógico (didáctico y organizativo) contemplamos elementos como: la estructura del curso es clara y facilita con claridad la identificación de cada una de las partes del mismo; si se e presenta un glosario de términos técnicos; si se declaran los objetivos, competencias y capacidades para la acción formativa; o si existe relación entre los objetivos, competencias y capacidades y los contenidos y actividades propuestos para la acción formativa. Y por último en el comunicativo se revisaban aspectos como si se propicia la interactividad entre estudiantes en la acción formativa, si se dispone de un cronograma general y particular de desarrollo de la actividad; o si existe una planificación en las sesiones realizadas a través de herramientas de comunicación asincrónica.

Para finalizar señalar que para su construcción nos apoyamos en los instrumentos elaborados por: Cabero (2004), Marcelo y otros (2006) y Cabero y López (2009a y b).

\section{3.- SUJETOS DE LA INVESTIGACIÓN.}

El perfil del profesorado objeto de nuestro estudio es el resultado del análisis de los datos aportados por el biograma. Según dichos datos podemos decir que:

El número de profesores que participaron en la investigación fueron 30, 14 profesoras y 16 profesores, pertenecientes a todas las Universidades públicas de Andalucía. De ellos el 53\% impartía 1 asignatura en la red, dando el 23\%, 2, y el 17\%, 3. Éstas eran por lo general impartidas por un único profesor (36\%) si bien nos encontramos con un $27 \%$

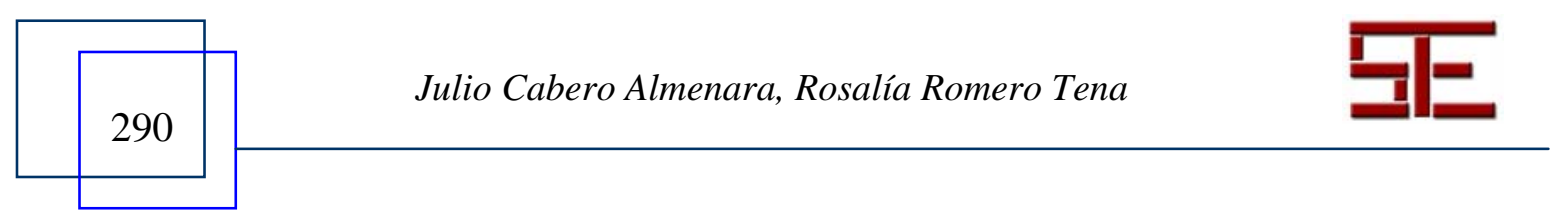




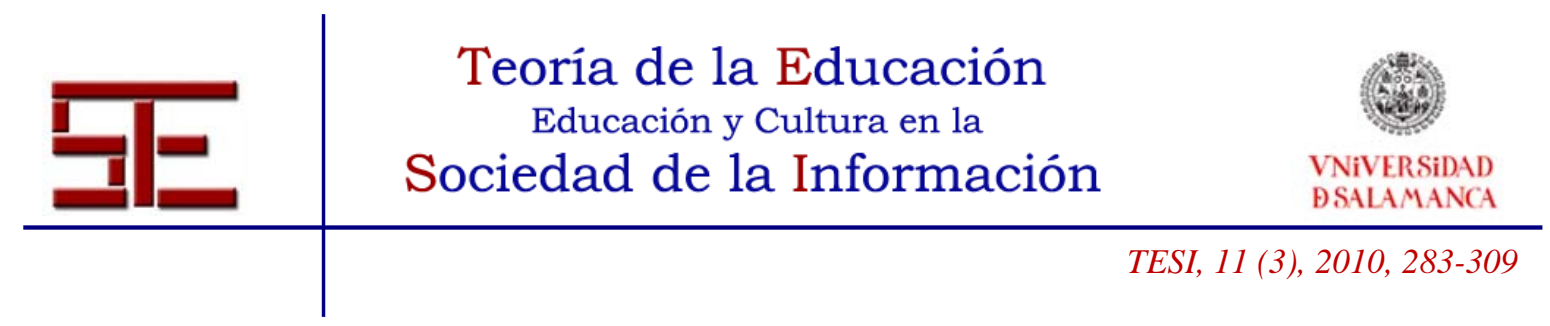

que eran impartidas por 2 y un 23\%, por 3 profesores. La gran mayoría, el 63\%, llevaba entre 5 y 15 años desarrollando su labor como docente universitario, mientras que el $37 \%$ restante supera ya los 15 años de ejercicio profesional. En el caso de la formación en red el 43\% llevaba entre 2 y 5 años, y el 54\% más de 5, sólo un 3\% llevaba 1. Por otra parte señalar, que el 54\%, desarrolla sus tareas docentes en el área de Ciencias Sociales y Jurídicas, seguidos de los de Científico-Técnicas (23\%), Ciencias de la Salud (20\%), y junto Artes y Humanidades (3\%). Para finalizar la descripción de la muestra, la mayoría (33\%) eran profesores Titulares de Universidad, seguidos de los Contratados/as Doctores/as y Colaboradores/as, con el 27\% y 23\% respectivamente, y de 13\% de Titulares de Escuela Universitaria y u 7\% de Profesores/as Asociados.

\section{4.- RESULTADOS DE LA INVESTIGACIÓN.}

\section{1.- Análisis de las entrevistas.}

Una vez realizadas las entrevistas, nuestro siguiente paso fue su transcripción y la lectura previa de algunas de ellas seleccionadas al azar para la construcción del primer borrador del Sistema de Categorías, que en cierta medida vino orientado por las preguntas que conformaron el protocolo de la entrevista. Tras varios reajustes establecidos por el equipo de investigación en reuniones de carácter internos, éste quedó definitivamente conformado por las siguientes dimensiones: a) modalidad e-learning, b) profesor; c) alumno; y d) Universidad.

A continuación presentamos la lista que conformaban las categorías y subcategorías de las dimensiones apuntadas. La primera. "Modalidad e-learning” se formó por: 1) Motivos (infraestructura, posibilidad TIC, interés personal, contenidos asignatura, y conocimiento TIC; 2) Presencial/Virtual: comunicación, tiempo, esfuerzo, productividad, completa-presencial, y contenidos; 3) Plataforma: personalización sistema., compatibilidad otros programas, asesoramiento, y asignatura; 4) Aspectos positivos: relación alumnos, rapidez(facilidad; individualización, y disponibilidad material; 5) Aspectos negativos: trabajo, uso haga, confusión, y organización alumnos; 6) Cambio rendimiento: afirmativo, negativo, y distinto; 7) Ratio: entre 10 y 25, entre 35 y 40, entre 50 y 65, entre 70 y 80, y tareas; 8) Evaluación: satisfacción alumnado, resultados diferentes evaluaciones, trabajos y prácticas, y complementaria; 9) Percepción compañeros: escépticos, ofrece ventajas, trabajo y no sustituye presencial. La segunda, "Profesor", incorporaba dos categorías: 1) Competencias: formación didáctica, dominio técnico, trabajo grupo, e interés; y 2) Formación: curso centro, curso universidad, autoformación y proyectos. La tercera, la referida a los “Alumnos", también estaba formada por dos: 1) Competencias (motivación, documentos, dominio técnico, y participación; y 2) Formación: manejo técnico, y docencia virtual. Y última, "Medidas", que estaba formada por una única categoría y nueve subcategorías:

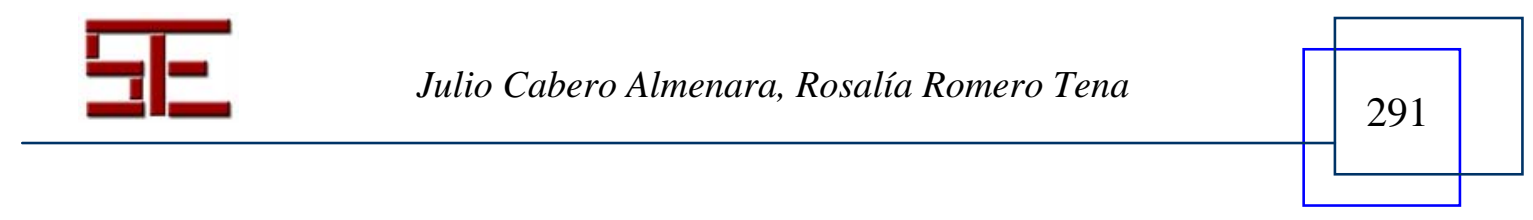




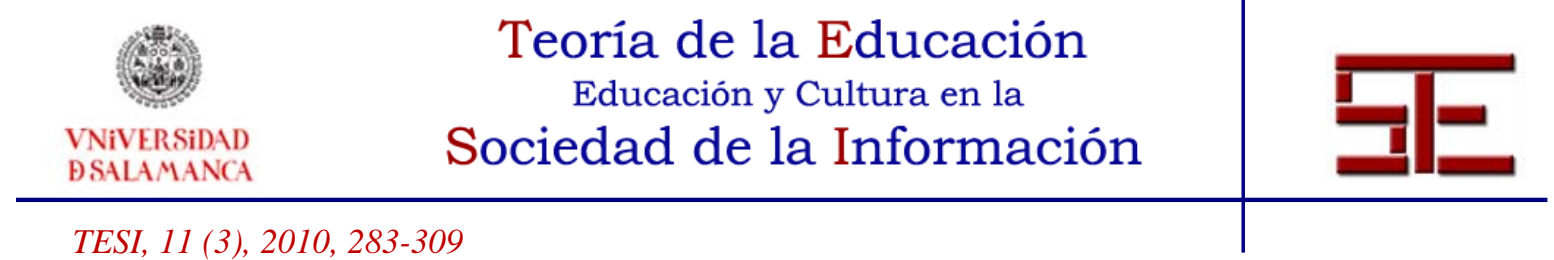

formación, valoración, plataforma, dotación técnica, dotación personal, interés profesorado, mejorarla en general, posibilidad TIC y posibilidades plataforma.

Por motivos de espacio, en este artículo sólo presentaremos los datos alcanzados a niveles de dimensión y categoría, y en ellas en las que más presencia han alcanzado. Los valores para las subcategoría, como la ampliación de la información, el lector interesado puede encontrarlas en la memoria de la investigación (Cabero, 2010).

La dimensión que obtuvo mayor representatividad fue MODALIDAD E-LEARNING ( $\mathrm{f}=293,58,13 \%$ ), lo cual era lógico, pues un gran número de preguntas iban destinadas a recoger todas aquellas referencias efectuadas por los profesores sobre el sistema de formación objeto de nuestro estudio en cualquiera de los aspectos relacionados con ella. A ella le han seguido la de PROFESORES ( $f=86,17,06 \%$ ), UNIVERSIDAD ( $f=69$, 13,69\%), para finalizar con las referidas a los ALUMNOS ( $\mathrm{f}=69,13,69 \%)$.

Comenzando nuestro análisis de las dimensiones, por lo que se refiere a la MODALIDAD E-LEARNING, en la tabla $\mathrm{n}^{\circ} 1$ pueden observarse las frecuencias y porcentajes alcanzados en cada una de categorías que la conformaban.

\begin{tabular}{|c|c|c|c|}
\hline \multicolumn{2}{|c|}{ CATEGORÍAS } & $F$ & $\%$ \\
\hline \multicolumn{2}{|c|}{ Motivos } & 30 & 10,23 \\
\hline \multicolumn{2}{|c|}{ Presencial/Virtual } & 45 & 15,35 \\
\hline \multicolumn{2}{|c|}{ Plataforma } & 19 & 6,48 \\
\hline \multirow{2}{*}{ Asp } & Positivos & 54 & 18,43 \\
\hline & Negativos & 25 & 8,53 \\
\hline \multicolumn{2}{|c|}{ Cambio rendimiento } & 27 & 9,21 \\
\hline \multicolumn{2}{|c|}{ Ratio } & 30 & 10,23 \\
\hline \multicolumn{2}{|c|}{ Evaluación } & 27 & 9,21 \\
\hline \multicolumn{2}{|c|}{ Percepción Compañeros } & 36 & 12,28 \\
\hline \multicolumn{2}{|c|}{ TOTAL } & 293 & $100 \%$ \\
\hline
\end{tabular}

Tabla $n^{\circ}$ 1. Categorías que forman parte de la Dimensión “MODALIDAD E-LEARNING”.

Como podemos observar en la tabla anterior, las 293 codificaciones se han repartido de la siguiente forma: “Aspectos positivos” con una frecuencia de 54 (18,43\%), seguida de "Presencial/Virtual" con una frecuencia de 45 y un porcentaje del 15,35, le sigue

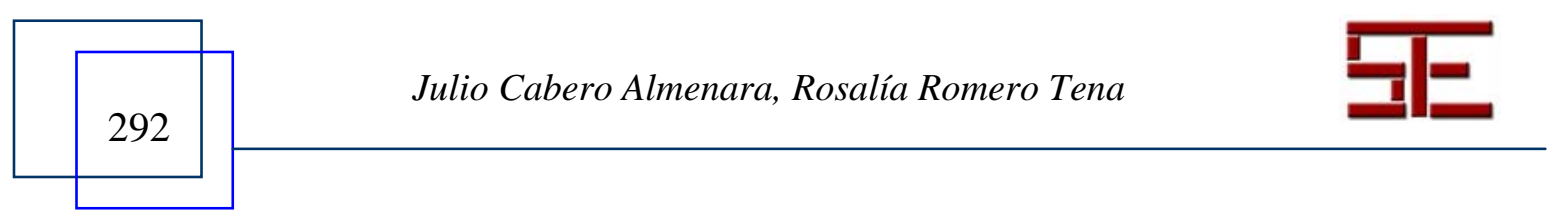




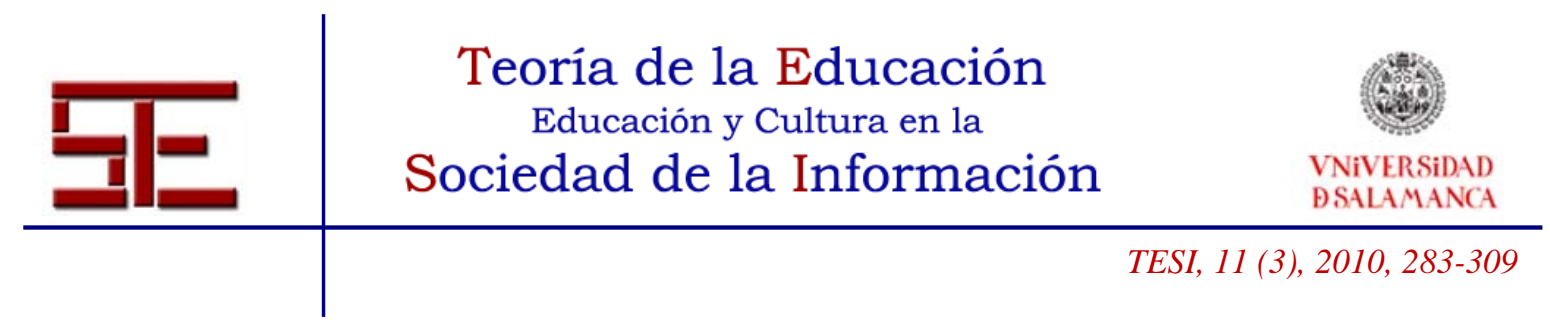

"Percepción de los Compañeros" con una frecuencia de 36 y un porcentaje del 12,28. La última categoría que ha tenido menos presentación ha sido la de "Plataforma" ( $\mathrm{f}=19$, 6,48\%). Existiendo entre el resto un porcentaje similar de presencia.

Estos valores alcanzados nos permiten tener una visión de la importancia concedida por los profesores entrevistados hacia las diferentes temáticas, destacándose los aspectos positivos así como los elementos de combinación de la formación presencial y virtual, y los problemas que la misma conlleva. Resulta significativo que la problemática que tanto ha ocupado espacio en la investigación en el terreno del e-learning, así como para los responsables técnicos de la Universidad, como es lo referido a las plataformas de teleformación, no tienen tanto impacto para el profesorado.

Por lo que se refiere a la categoría “Aspectos Positivos” los aspectos más destacados por los docentes ha sido la "Disponibilidad de Material" con un 31,48\% ( $\mathrm{f}=17$ ) de representatividad. Esta subcategoría hace referencia a aquellos comentarios que reflejan la posibilidad de tener acceso a una variedad de material y recursos de consulta y trabajo para el alumno. Le sigue "Comunicación" que se refiere a comentarios que reflejan las posibilidades de comunicación que ofrece esta modalidad. En este caso la frecuencia obtenida es de 13 (24,07\%). También podemos destacar la "Individualización" pero con un porcentaje que no llega al $15 \%$ del total de las referencias efectuadas en esta categoría y, en este caso, se recogen comentarios que aluden a la posibilidad que le brinda al alumnado esta modalidad de formación de ir a su ritmo en los aprendizajes de una materia.

Ejemplos textuales de las subcategorías más significativas de Aspectos Positivos tenemos por un lado los referidos a la "Disponibilidad Material":

“La ventaja para los profesores es que sabemos que estamos poniendo a disposición de los alumnos los mejores medios posibles, y tenemos a nuestra disposición una información sobre la evolución, forma de trabajar y cantidad de trabajo que desarrollan nuestros alumnos que en la enseñanza simplemente presencial no se tiene.”. (A.P. DISPONIBILIDAD MATERIAL. E-1).

Y por otro, los referidos a la “Comunicación”:

“... la posibilidad de establecer una mayor comunicación”. (A.P. COMUNICACIÓN. E-9).

Estos Aspectos Positivos han sido matizados por los profesores en diferentes aspectos, y así nos encontramos con que uno de estos es la cantidad de información que se pone a disposición de los estudiantes que puede ser utilizada en el momento que éstos lo consideren oportuno y además sin la marginación de ninguno de ellos, y el volumen de información que los profesores tienen respecto al trabajo realizado por los estudiantes, como podemos observar en siguientes los comentarios:

“... los profesores es que sabemos que estamos poniendo a disposición de los alumnos los mejores medios posibles, y tenemos a nuestra disposición una información sobre la evolución, forma de trabajar y cantidad de trabajo que desarrollan nuestros alumnos que en la enseñanza simplemente presencial no se tiene.” (A.P. E-1)

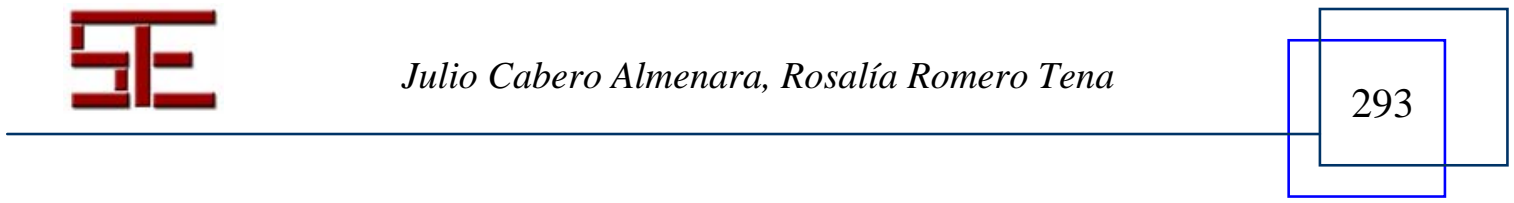




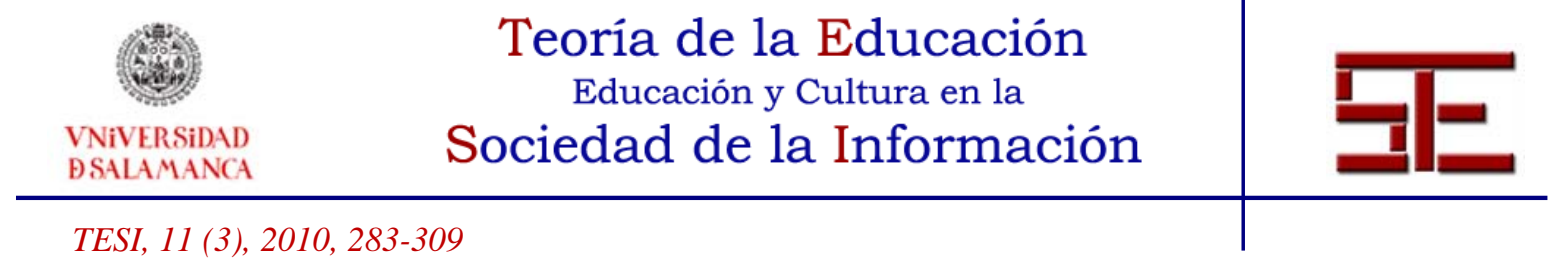

Concretando lo anterior, hay un grupo de profesores que perciben su utilidad no sólo por la cantidad de información que se pone a disposición de los estudiantes, sino que la misma se especifica en una diversidad de recursos, como podemos observar por el siguiente comentario:

“En primer lugar la consideración, la posibilidad de incluir contenidos multimedia, esa es una posibilidad yo creo que importante la posibilidad de incluir videos, cualquier otro recurso existente o disponible en la web y por otra parte la posibilidad de lo que decía antes de implantar ese sistema de evaluación formativa mediante la realización de test periódicos,....” (A.P. E-22).

Aunque también hay un grupo de profesores que matizan estos aspectos en la amplitud de comunicación que el sistema tecnológico permite, amplitud que facilita la relación directa profesor-estudiantes:

“... lo positivo es que nosotros podamos interactuar también con los alumnos, fundamentalmente a través de los sistemas de comunicación, cosa que sin la tecnología sería muy difícil.” (A.P. E-2).

No podemos olvidarnos de aquellos que destacan como el aspecto más significativo el de la individualización de la enseñanza y acción tutorial:

“Trabajo a ritmos distintos, en función de las necesidades de cada uno” (A.P. E-10) y "Tienen la posibilidad de las tutorías virtuales mediante correo electrónico y chats con el profesor responsable, tratando de resolverse cualquier duda o inquietud en menos de 24h” (A,P. E-15).

Aunque los "Aspectos Negativos" no son los que han obtenido una frecuencia siguiente a la de Aspectos Positivos, si creemos importante comentar las subcategorías más sobresaliente en esta categoría por considerar aportan ideas claves para delimitar los resultados antes destacados. En sus subcategorías las más recalcadas han sido: "Trabajo" que se refiere los comentarios que aluden al mayor trabajo que supone la modalidad e-learning sobretodo al comienzo para estos profesores. Esta subcategoría ha obtenido una frecuencia de 12 y un porcentaje del 48\% de total de las referencias de esta categoría; y "Uso haga” que se refiere a la falta de productividad que supone el mal uso de este modelo para el desarrollo de una asignatura, aquí estamos hablando de una frecuencia de 7 y un porcentaje del $28 \%$ del total.

Por lo que se refiere al "Trabajo” se llega a destacar:

“...la dedicación que debiera para tener un campus virtual en condiciones”. (A.N. TRABAJO. E12) y "El problema más importante es que requiere que el profesor esté continuamente formado en entornos virtuales y en los nuevos programas y tecnologías que van surgiendo”. (A.N. TRABAJO. E-24).

Y en el caso de "Uso haga":

“... dos aspectos clave: a) existe un peligro latente a convertir la plataforma digital en una reprografía doméstica, lo que lleva a una banalización de la enseñanza virtual, y a unas malas prácticas que desvirtúan las auténticas y nuevas posibilidades que entrañan los recursos digitales; b) el uso indiscriminado del correo electrónico por parte de los alumnos para realizar preguntas de todo tipo y a cualquier hora al profesor”. (A.N. USO HAGA. E- 8)

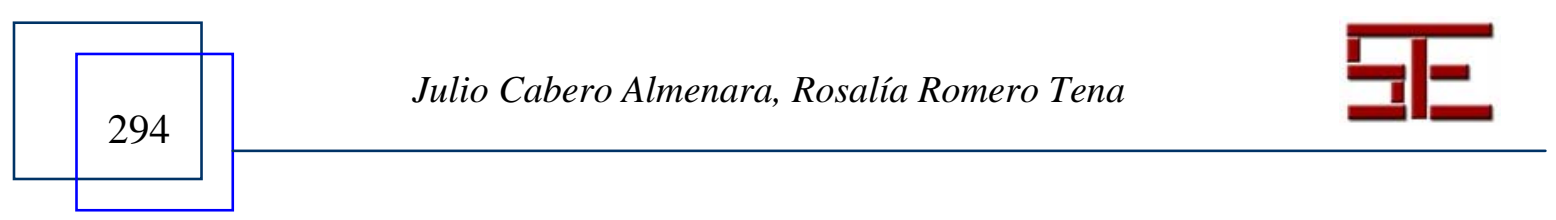




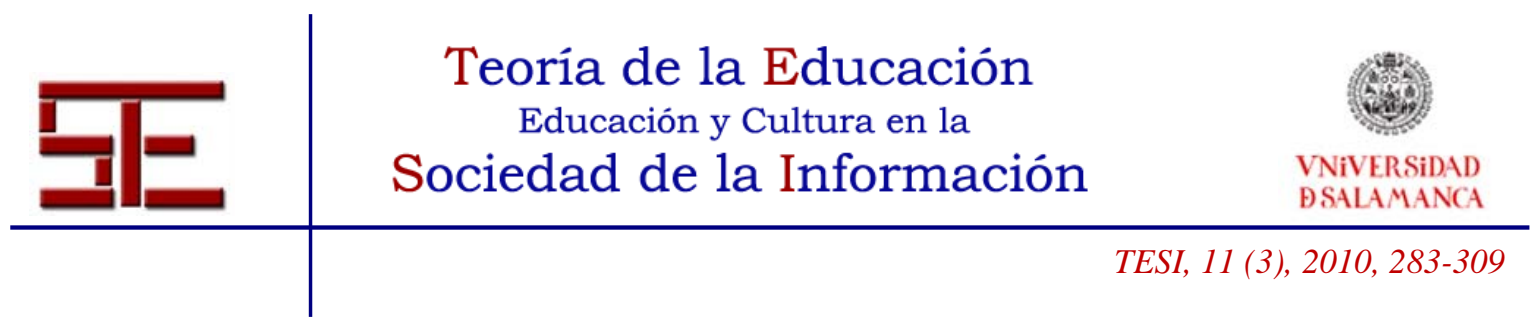

Realizando un análisis más pormenorizado de los aspectos que son percibidos como negativos por parte de los profesores, nos encontramos en primer lugar con el fuerte esfuerzo y trabajo que esta estrategia de formación requiere para los profesores, como fácilmente podemos observar en los siguientes comentarios de nuestros profesores:

“... la sobrecarga de trabajo que supone. Antes sabía que mi dedicación a las tutorías era de 6 horas a la semana, ahora ese tiempo puede ser sólo de un día, lo cual hace que a lo largo de la semana el número de horas de dedicación sea muy superior a aquello que la Universidad nos reconoce.” (A.N. E-1).

Hay también un grupo de profesores que señalan como negativo las características y especificidades del entorno tecnológico utilizado:

“... las plataformas virtuales no se adaptan aún a todos los requerimientos que en particular serían necesarios, como capacidad de gestión de archivos, o falta de recursos técnicos para poder sacar partido a las posibilidades que sí tiene la plataforma empleada”. A.N. E-5).

Y no nos podemos olvidarnos de la percepción de la falta de capacitación de los docentes, aunque si bien no ha aparecido mucho en los comentarios de nuestros entrevistadores, pues recuérdese que eran profesores considerados de "buenas prácticas" y por tanto con verdadera experiencia sobre el tema:

“Falta de formación en el manejo de esta herramienta de trabajo” (A.N. E-19).

La siguiente categoría que apareció con mayor frecuencia es "Presencial/Virtual”. En ella se han recogido comentarios relacionados con todos los aspectos y/o elementos que hacen inevitablemente una comparación entre la modalidad de formación presencial y la virtual. De las subcategorías que se incluyen dentro de ella tenemos las dos más representativas. La primera es "Tiempo", que hace referencia a la mayor cantidad de tiempo que hay que invertir en la enseñanza virtual más que en la presencial, se hace hincapié en el inicio de la misma. "Tiempo" obtuvo una frecuencia de 21 y un porcentaje de 46,67\% del total de los comentarios. A esta le sigue "Esfuerzo", que hace referencia al esfuerzo que se hace en la elaboración de una asignatura virtual así como en la actualización continuada de la misma. En este caso estamos hablando de una frecuencia de 19 y un porcentaje de 42,22\% de las referencias efectuadas en esta categoría.

En este aspecto de lo presencial/virtual los comentarios de los profesores fueron muy diversos, y un gran volumen de ellos iban destinados al esfuerzo que le supone:

"Pues creo que la formación virtual requiere más tiempo y más esfuerzo que la presencial, porque de alguna manera,... ya se abre el abanico de horario disponible para el alumnado de alguna manera y se requieren nuevos recursos, se requiere el estar en un continuo perfeccionamiento, en un continuo proceso de aprendizaje por parte del profesorado también, entonces, creo que requiere más tiempo y más esfuerzo por parte del profesor, pero también creo que la recompensas son mejores.” (PR/VIR E-26).

Aunque en este esfuerzo también tiene que ver el número de alumnos que tienen, como podemos observar por el siguiente comentario que nos realizó un profesor:

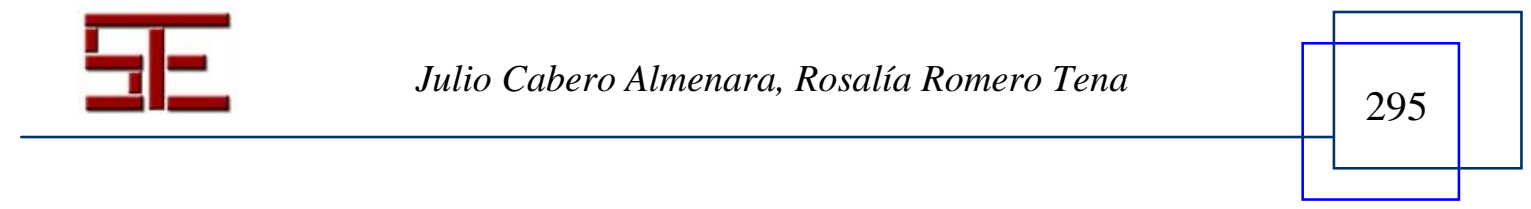




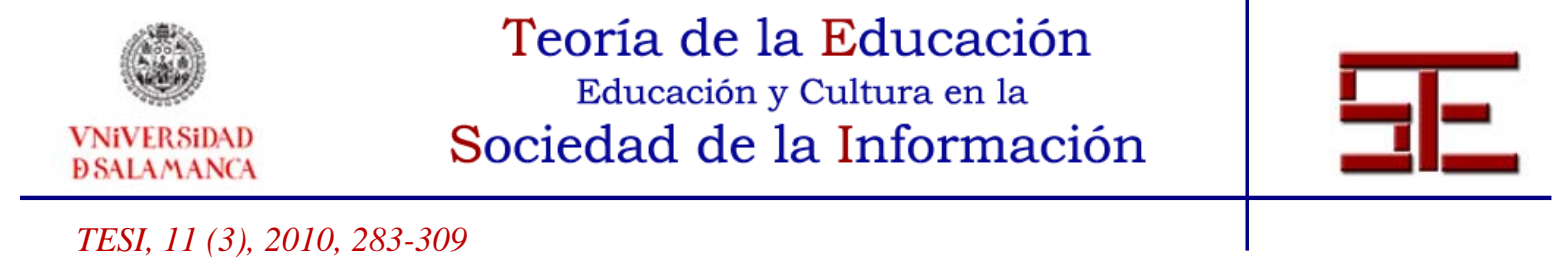

"El esfuerzo es mayor en cuanto a la cantidad de tiempo que se ha de tener para atender de forma satisfactoria a todos los recursos y, sobre todo, debido al alto índice de alumnos matriculados que siempre superan los 120 alumnos.” (PR/VIR E-23).

Hay también algunos profesores que llaman la atención respecto a la necesidad de que los capaciten para el uso didáctico y no meramente en el referente técnico del manejo de la plataforma:

\begin{abstract}
"La formación virtual en mi universidad creo que se encuentra muy sesgada en lo que se refiere al dominio tecnológico. Cuando hablo de dominio tecnológico me estoy refiriendo a que la mayoría de los esfuerzos van dirigidos hacia esos aspectos, y muy poco en lo referido a las posibilidades pedagógicas del uso y la incorporación de todas las tecnologías en la universidad. Por ejemplo, te enseñan a usar Moodle, o cualquier otra plataforma, pero no te enseñan todas las posibilidades didácticas y pedagógicas que la herramienta tiene y las cuales se podría explotar, dominar y manejar.” (PR/VIR E-9).
\end{abstract}

Continuamos con "Percepción de los Compañeros", a través de la cual se recogen aquellos comentarios que reflejan la actitud, comportamiento, etc., mostrada por los compañeros que les rodean, el primero de ellos que obtuvo mayor frecuencia (12) fue "Ofrece Ventajas" y con un porcentaje del 33.3\% del total de los comentarios efectuados. Esta subcategoría refleja el reconocimiento, o no, y el valor, o no, por parte del profesorado de las ventajas o desventajas que este sistema ofrece para la docencia.

Las percepciones que sus compañeros suelen tener respecto a la utilización de la red como elemento formativo es bastante positiva, y destaca sobre los comentarios que implicarían una valoración más negativa. Ejemplos significativos de dichas subcategorías son:

“... lo ven como una herramienta muy importante y luego yo como doy cursos de formación, yo creo que mucha gente desconoce las posibilidades de la plataforma y todo lo que les puede ofrecer la plataforma, sin duda claro con parte de esfuerzo de, de mucho esfuerzo por parte del profesorado”. (P.C. OFRECE VENTAJAS. E-25).

Le sigue "No sustituye Presencial", que se refiere a que para determinados profesores esta modalidad de enseñanza virtual no puede sustituir a la presencial. En ocasiones son aclaración de lo que cada una aporta. En este caso la frecuencia obtenida es de $10 \mathrm{y}$ el porcentaje es del 27,78. Cerca de ella se encuentra "Escépticos" que se refiere a la actitud del profesorado ante la modalidad e.-learning, llegando a pensar que tan sólo es un lugar para colgar los apuntes, aquí la frecuencia obtenida es de 9 y el porcentaje alcanzado de $25 \%$. Ejemplos de ellas son:

“... la mayoría no se complican, dan sus clases tradicionales y cobran un sueldo básico por esto”. (P.C. NO SUSTITUYE PRESENCIAL. E-15) y "Aún creo que un numeroso grupo de profesores considera la enseñanza virtualizada como algo secundario y de poca relevancia”. (P.C. ESCÉPTICOS. E- 24).

En este aspecto de la percepción de los compañeros, las respuestas que nos hemos encontrado han sido muy diversas, algunas se refieren a las percepciones negativas:

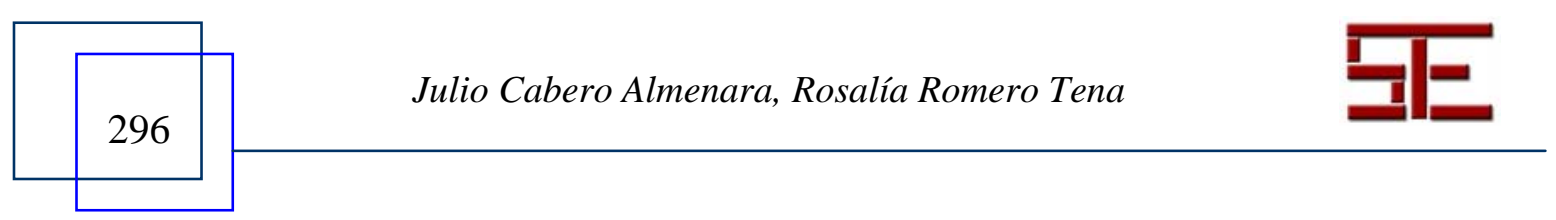




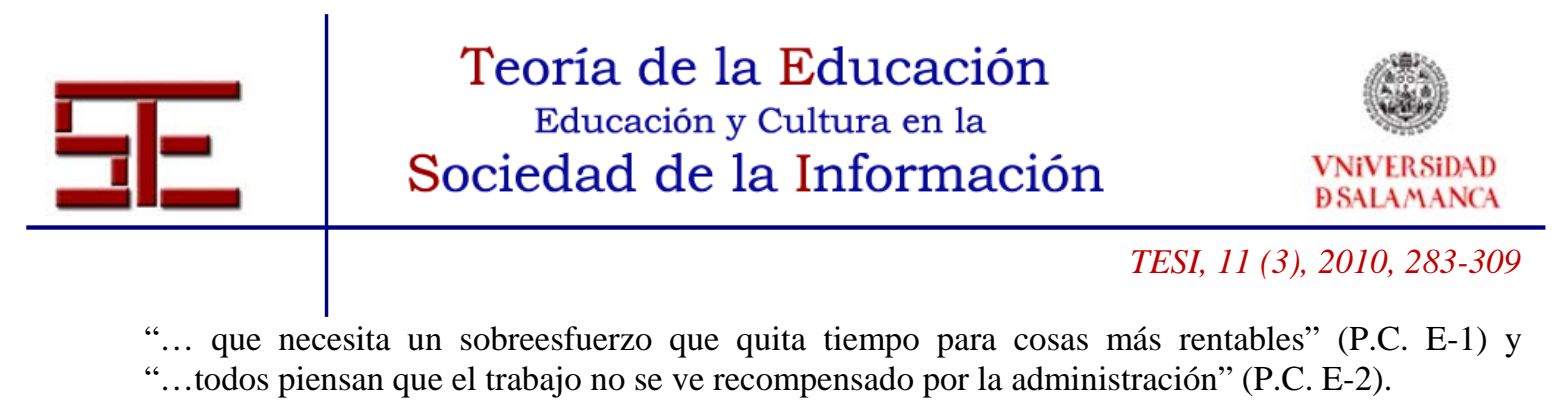

Hay también un grupo de profesores que opinan que sus compañeros no se incorporan por la dificultad que ello trae consigo:

“Se les hace un monte. Vislumbran mucha dificultad y mucha dedicación” (P.C. E-7)

"Dificultosa y un coste excesivo en tiempo" (P.C. E-19).

Por lo que se refiere a la dimensión PROFESOR, con ella se pretendía recoger todos aquellos comentarios efectuados por los docentes relativos a sí mismos y a su tarea a la hora de incorporar a su docencia una o varias asignaturas en la modalidad elearning. La frecuencia obtenida por esta dimensión es de $86(17,06 \%)$ y en la tabla $\mathrm{n}^{0}$ 2 se presentan las frecuencias y porcentajes, para la dimensión que la conforman.

\begin{tabular}{|l|c|c|}
\hline \multicolumn{1}{|c|}{ CATEGORÍAS } & $f$ & $\%$ \\
\hline Competencias & 47 & 54,65 \\
\hline Formación & 39 & 45,35 \\
\hline TOTAL & 86 & $100 \%$ \\
\hline
\end{tabular}

Tabla n 2. Categorías que forman parte de la Dimensión "Profesor”.

Comenzaremos por describir la categoría "Competencias", ya que fue la obtuvo la mayor frecuencia de las dos. En ella se ha intentado recoger todas aquellas referencias que aluden a los aspectos importantes a considerar para poder llevar una formación elearning con éxito. De las subcategorías que la integra ha sido "Dominio Técnico" la que ha obtenido mayor frecuencia (28) y ha conseguido casi el $60 \%$ de las referencias efectuadas. Esta subcategoría recoger aquellos comentarios que se refieren la necesidad de un dominio técnico relativo a manejo del ordenador y de la plataforma.

Le sigue "Formación Didáctica", que alude a comentarios que muestran que una de las competencias básicas necesarias para llevar a cabo una modalidad virtual es la didáctica. Esta subcategoría ha obtenido casi el 30\% de las referencias efectuadas, la mitad que la Dominio Técnico pero lo suficientemente representativa como para comentarla y aportar sus comentarios más representativos.

En este apartado de las competencias, los profesores nos realizaron una serie de matizaciones respecto a las que se deberían tener para desenvolverse en la formación virtual, que eran independientes de la necesidad de conocer el funcionamiento técnicoinstrumental de la plataforma. Algunos de los comentarios han sido:

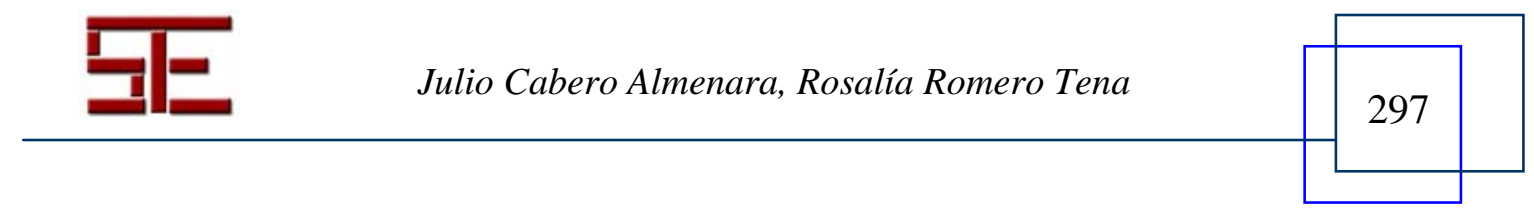




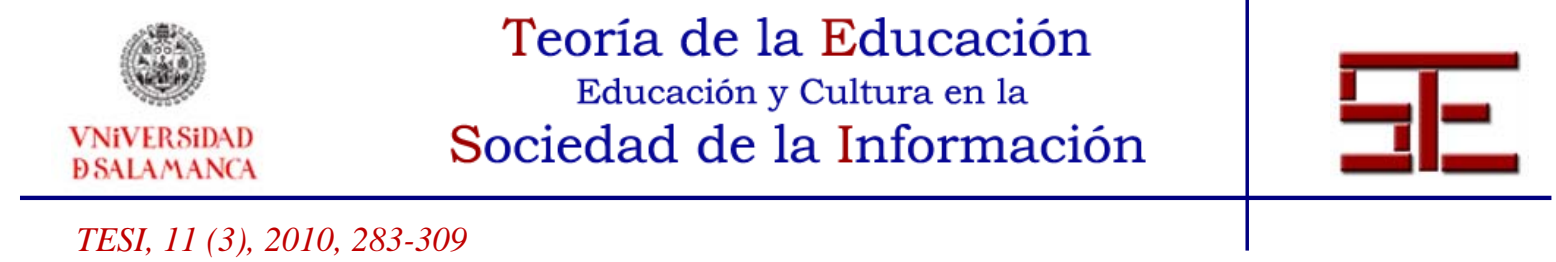

“...saber diseñar y crear contenidos para este nuevo medio, no vale un pdf con 30 folios, y ahí va el tema, hay que saber diseñar instrumentos de evaluación de manera adecuada, y que recojan de manera práctica los contenidos esenciales para que los alumnos aprendan haciendo.” (C. E-1)

“Competencias comunicativas e interpersonales. Ser capaz de crear contenidos y entornos de aprendizaje atractivos, orientar al alumnado en cómo utilizar las distintas fuentes de conocimiento, potenciar la participación del alumnado, etc.” (C. E-3)

"Formación”, es la segunda categoría que hemos incluido en PROFESOR. En ella pretendemos aglutinar todos aquellos comentarios que se refieren a la procedencia del conocimiento necesario para llevar a acabo una formación on-line. En ella hay dos subcategorías que parecen destacarse con relación a las demás y son "Cursos Universidad” y “Autoformación”.

De ellas la que ha obtenido la frecuencia más alta son "Curso Universidad" con 18 y "Autoformación" con 17, luego prácticamente ambas se disputan la mayoría de los comentarios efectuados por los docentes. De estas dos subcategorías podemos inferir que la mayoría de los docentes han adquirido su formación para impartir la modalidad e-learning por medio de Cursos realizados en la Universidad exactamente el 46,15\% $(\mathrm{f}=18)$ seguidos de los que se han Autoformado para ello que son el 43,59\% 8f=17); como puede observar en los siguientes comentarios:

“Diversos cursos del ICE”. (F. CURSOS UNIVERSIDAD. E-6)

“...a mí nadie me dio (risa) formación ninguna, es decir, pinchas, miras, te documentas, miras manual, trasteas y luego te lanzas a dar curso de formación”. (F. AUTOFORMACIÓN. E-11).

Otra de las dimensiones de nuestro sistema categoríal era la de UNIVERSIDAD, con la que se pretende recoger todos aquellos comentarios efectuados sobre los diferentes elementos importantes a tratar en el contexto donde se está llevando a cabo la modalidad virtual. La frecuencia obtenida por esta dimensión es de 69 y constituyendo el 13,69\% del total de las referencias recogidas en la entrevistas. En la tabla $n^{\circ} 3$, se presentan las frecuencias y porcentajes de las dos categorías que la conforman.

\begin{tabular}{|l|c|c|}
\hline \multicolumn{1}{|c|}{ CATEGORÍAS } & $f$ & $\%$ \\
\hline Medidas & 47 & 68,12 \\
\hline Percepción formación virtual. & 22 & 31,88 \\
\hline TOTAL & 69 & $100 \%$ \\
\hline
\end{tabular}

Tabla n 3. Categorías que forman parte de la Dimensión “UNIVERSIDAD”.

Dentro de “Competencias” la subcategorías más destacadas son “Valoración”, con una frecuencia de 15 (31,91\%). Esta recoge aquellos comentarios que reflejan la falta de valoración por parte de la Universidad del trabajo que se está realizando en la enseñanza virtual se habla de considerarlo en el POD o como mérito docente.

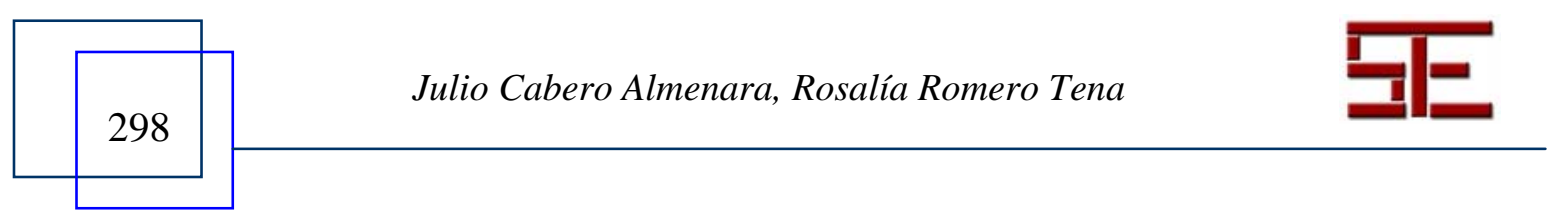




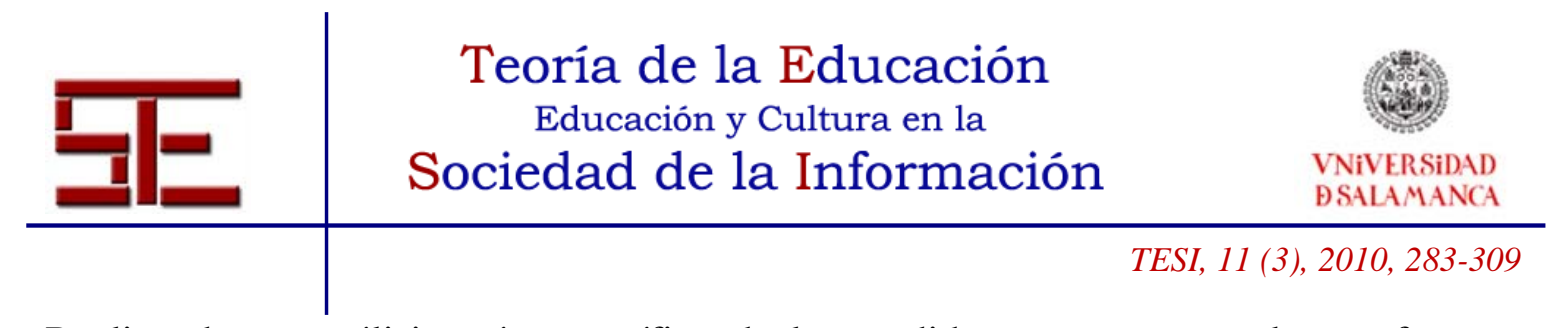

Realizando un análisis más específico de las medidas que proponen los profesores. Algunos comentarios aludían a la necesidad de reconocimiento por parte de la Institución:

“...básicamente el reconocimiento del trabajo que están haciendo los profesores del ámbito. De alguna forma hay que reconocerlo, no se la fórmula; si a través de reconocimiento de créditos de mayor carga, si reconocimiento económico.” (M. E-2).

Le sigue "Formación" que alude a la necesidad de crear estrategias formativas para que exista una formación por parte de la Universidad para profesores y alumnos en formación virtual. Esta subcategoría obtuvo el 29,79\% de los comentarios efectuados y la frecuencia fue de 14. También podríamos destacar "Dotación Técnica” que reflejan la necesidad de una dotación técnica mayor a la que actualmente existe y que obtuvo una frecuencia 10 y un porcentaje del 21,28\% del total de la categoría. En este aspecto es también de destacar que algunos profesores insistían en las necesidades de formación para los alumnos:

“También se debería incorporar cursos de formación al alumnado en el primer cuso de licenciatura." (M. E-3).

Aunque también algunos profesores que reclaman más medios para desarrollar este tipo de actividades y la creación de servicios de apoyo al profesorado:

“...es muy importante que haya un buen servicio de atención al profesorado en el tema de elearning, unos buenos centros de enseñanza virtual, que haya personas tecnológicamente competentes que puedan ayudar al profesorado a desarrollar los diferentes tipos de material que necesiten, a enseñarles nuevas orientaciones, etcétera, etcétera.” (M. E. 18).

"Percepción Formación Virtual” es la otra categoría que nos ofrece unidades de significado a la dimensión UNIVERSIDAD. En ella se han recogido todos aquellos comentarios que reflejan de alguna manera la visión que ellos creen tener de cómo es percibida la formación virtual por la propia Universidad.

Dentro de las subcategorías, la del Interés Profesor son comentarios que reflejan hay una falta de interés por parte del profesorado, obtuvo el 31,82\% de las referencias efectuadas. Le sigue Mejorarla en General que hace referencia de forma generalizada a que hay que mejorar pero sin concretar ningún aspecto en concreto, en este caso el porcentaje obtenido es del 27,27\%, luego nos encontramos con Posibilidades Plataforma con 22,73\% y finalizamos con Posibilidades TIC con un 18,18\% de la representación total de los comentarios efectuados.

En este aspectos los comentarios realizados nos indican que no existe una imagen unánime al respecto, y así nos encontramos con aquellos que no tienen muchas esperanzas es que este sistema llegue a implementarse completamente y su proceso de extensión va más lento de lo que cabría esperar y su extensión es más lenta de lo que cabría esperar, y ello se debe a diferentes motivos:

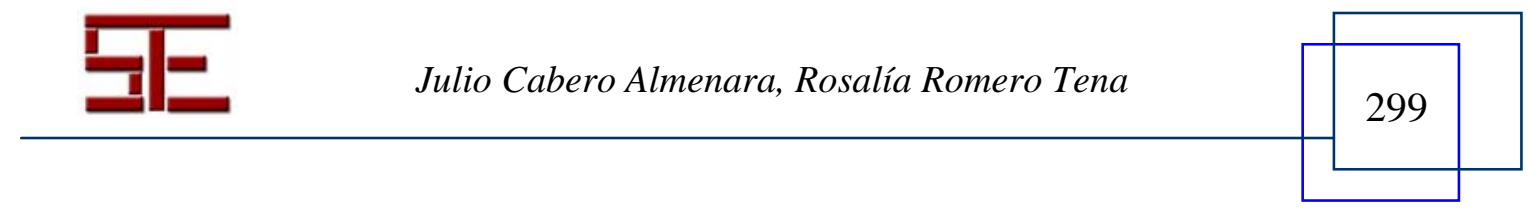




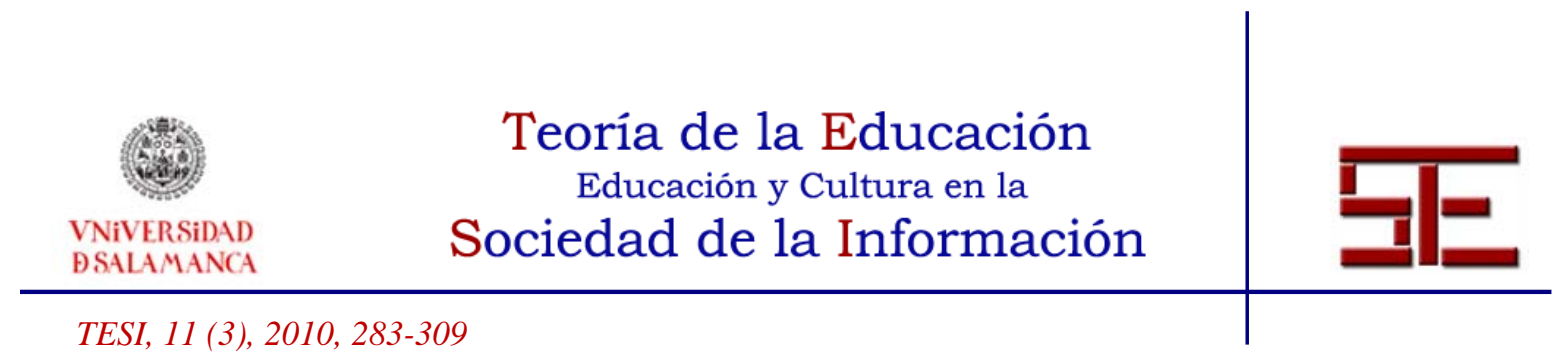

“...el reconocimiento del trabajo que están haciendo los profesores del ámbito. De alguna forma hay que reconocerlo, no se la fórmula; si a través de reconocimiento de créditos de mayor carga, si reconocimiento económico.” (P.F.V. E-2)

Y para ello los profesores de nuestra investigación apuntan algunas medidas:

“...falta motivar a más profesores tanto de asignaturas básicas como de asignaturas avanzadas.” (P.F.V. E-15)

"Progresivamente va creciendo el número de profesores que han aprendido y utilizan la plataforma virtual que pero siguen siendo más los que desconocen su uso y no parecen interesados en ella (la identifican con algo complicado que les robará tiempo).” (P.F.V. E-17).

Nuestra última dimensión era la de $A L U M N O$, que es la que obtuvo la menor frecuencia de todas, exactamente 56 , formando el $11,11 \%$ del total de las referencias efectuadas en las entrevistas. En la tabla $\mathrm{n}^{\circ} 4$, se ofrecen las frecuencias y porcentajes obtenidos en las categorías de dicha dimensión.

\begin{tabular}{|l|c|c|}
\hline \multicolumn{1}{|c|}{ CATEGORÍAS } & $F$ & $\%$ \\
\hline Competencia & 31 & 55,36 \\
\hline Formación & 25 & 44,64 \\
\hline TOTAL & 56 & $100 \%$ \\
\hline
\end{tabular}

Tabla n 4. Categorías que forman parte de la Dimensión “ALUMNO”.

Dentro de la categoría “Competencias” fue la subcategoría "Dominio Técnico" que hace referencia a comentarios que destacan la importancia del manejo del ordenador por parte de alumno así como de la plataforma, la que obtuvo un porcentaje mayor con el $45,16 \%$. A esta subcategoría le siguió "Documentos" que reflejan los comentarios efectuados que aluden a la importancia de saber utilizar la documentación que deposita el profesor en la plataforma para el desarrollo de la asignatura, incluye el trabajar con documentos en diferentes idiomas, esta obtuvo un $25,81 \%$.

Las matizaciones que nuestros profesores realizaron respecto a las competencias que percibían que debían de poseer los estudiantes que cursaban asignaturas virtuales fueron diversas, y que nos permiten obtener ideas sobre las acciones formativas que se deben realizar con los estudiantes:

“...que sean capaces de diseñar su propia estrategia de aprendizaje a partir de los recursos que se les ofrece, además de hacerse responsable de su propio aprendizaje.” (C. E-1)

“Conocimiento básico de herramientas informáticas.” (C. E-26)

"Integración de conocimientos, capacidad de relación y encaje de una mayor cantidad de información, sin recurso memorístico al modelo con insistencia en la creatividad para su uso.” (C. E-5.)

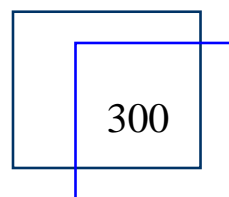

Julio Cabero Almenara, Rosalía Romero Tena

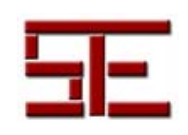




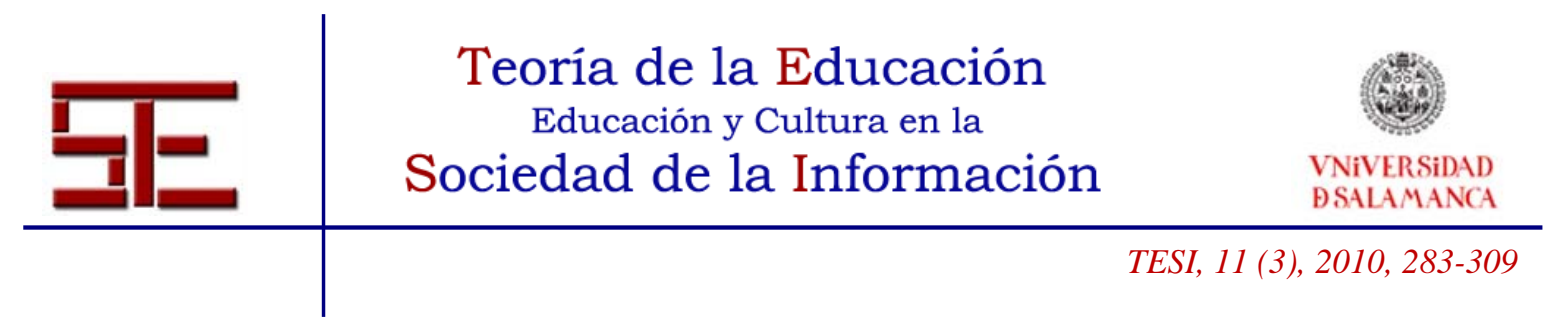

Hay también profesores que sugieren la necesidad de un cambio de mentalidad en el profesorado:

“...que los alumnos siguen con el chip de la enseñanza tradicional, entre otras cosas porque la mayoría de las asignaturas son así. Y con la enseñanza en base a las NNTT probablemente se necesiten implicar más en el día a día de llevar la asignatura, y eso no les está resultando del todo sencillo.” (C. E-2).

Finalmente, es Formación la última categoría que describiremos, y destacar de ella que la subcategoría más sobresaliente hay sido "Manejo Técnico" que ha obtenido el 76\% de la representación de las dos subcategorías que la forman ya que "Docencia Virtual” sólo ha obtenido el 24\%. Ejemplos de ambas nos darán una visión de las ideas más destacadas de los profesores.

\section{2.- Análisis de los materiales utilizados por los profesores.}

Como señalamos anteriormente el instrumento que utilizamos pretendía recoger información en tres tipos de diseño: técnico, pedagógico y comunicativo. Por lo que se refiere al Diseño Tecnológico, y a la luz de los resultados obtenidos tras el análisis del sistema de observación, podemos decir que los materiales de e-learning presentados por los profesores participantes, cuidan especialmente los sistemas de navegación, ya que encontramos el ítem "El sistema de navegación del programa funciona perfectamente" como el que más índice de acuerdo positivo ha obtenido, el 95,8\% de los profesores participantes encuentran que sus materiales presentan esta característica. En orden decreciente nos encontramos con "Se aportan los elementos técnicos correctos que el estudiante debe tener para poder seguir el curso", el $91.7 \%$ de los profesores encuentran esta cualidad en sus materiales, con el mismo porcentaje $79.2 \%$ nos encontramos con los ítems "todas las páginas no presentan error de conexión” y "las imágenes, clip de vídeo y animaciones se encuentran bien instaladas dentro del programa”, con un $70.8 \%$ de acuerdo "los programas que deben ser descargados e instalados realizan la operación de forma sencilla", con un $66.7 \%$ de acuerdo los ítems "los programas que deben ser descargados e instalados realizan la operación de forma rápida” y “existen elementos gráficos”, el 62.5\% de los docentes afirman que "no existen hiperenlaces vacíos”, el $54.2 \%$ exponen que en sus materiales "existen presentaciones audiovisuales", la mitad de los profesores (50\%) indican que en sus materiales "se indican las competencias mínimas tecnológicas que debe tener el estudiante para poder desenvolverse con claridad en la acción formativa” y que "el estudiante cuenta con un sistema de ayuda” y en último lugar, solo el $16.7 \%$ afirma que en sus materiales "se ofrecen en los clip de vídeos diferentes niveles de resolución”.

A la luz de los resultados alcanzados, podemos decir, que en el $100 \%$ de los casos “todas las páginas del curso pueden ser identificadas a través de su título” y “existe uniformidad en los colores de los botones y elementos de enlace”. El 98\% de los profesores participantes nos indica que la plataforma que utiliza tiene "herramientas de comunicación asincrónicas”, el 95.8\% dice que “existe uniformidad en los iconos del

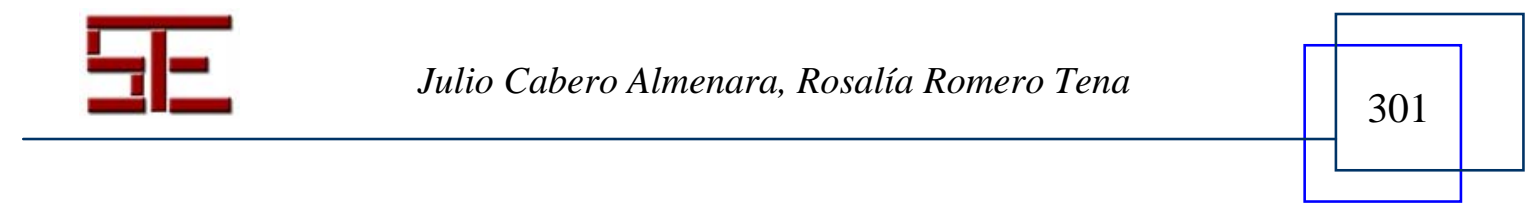




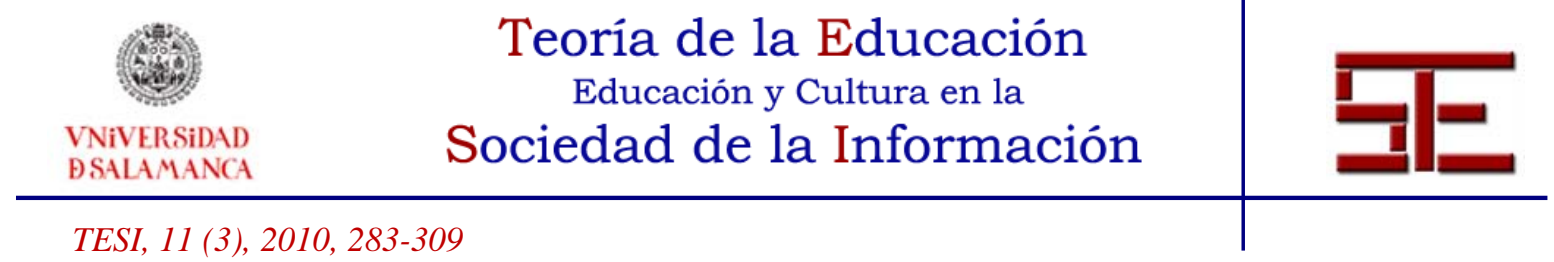

curso que realizan las mismas acciones y operaciones" y que los "los elementos de navegación están situados en los mismos lugares en todas las pantallas”. El 87.7\% nos comenta que "desde cualquier parte del curso se le ofrece al alumno la posibilidad de ir al comienzo del curso". El 83.3\% coincide en que la plataforma utilizada incluye: “Calendario/Cronograma”, "Existe un mapa de navegación”, "Posibilidad de visualizar la totalidad de las pantallas de curso, sin cambiar la resolución de la pantalla", "El tamaño de las imágenes guarda relación con el tamaño del texto" y "Tablón de anuncios". El 70.8\% nos dice que en la plataforma utilizada, se incluyen "Referencias a listas de conectados". El 62.5\% posee en su plataforma "Posee herramientas de presentación de ejercicios de autoevaluación”, “Ofrece la posibilidad de desarrollar por los estudiantes trabajos grupales, y trabajos colaborativos", y "Los elementos multimedias se escuchan y se ven con claridad y nitidez". El 58.5\% de los docentes afirma que en su plataforma se incluyen "Herramientas de comunicación sincrónica”, el $33.3 \%$ indica que se incluyen "elementos que facilite la accesibilidad de todos los estudiantes a la información: incrustación de elementos "alt" para describir las imágenes, la información visual, audiovisual y multimedia se presenta también por otras vías alternativas,...”, el 29.2\% “Tiene herramientas para la corrección de los ejercicios por parte de los estudiantes", el 12.5\% incluye "Flexibilidad y variedad en la secuencia de realización de actividades" y por último solo el 8.3\% manifiesta la "Existencia de pizarra virtual” en la plataforma que usa.

La segunda de las dimensiones de nuestra ficha de análisis, se centraba específicamente en el Diseño Pedagógico. Ésta estaba compuesta por 45 ítems, la mayoría de los ítems que componen esta dimensión tienen una presencia superior al $50 \%$ en los materiales diseñados por los profesores encuestados. Luego podemos señalar que son materiales donde se han cuidado este tipo de aspectos.

Por lo que se refiere al "Diseño Comunicativo", que el ítem que alcanza un mayor porcentaje, y teniendo en cuenta el valor alcanzado (100\%), podemos decir que en todos los materiales analizados, "El lenguaje utilizado en el curso está al nivel del grupo de alumnos receptores de la actividad formativa". En el 87.5\% de los casos "Existe un apartado informativo respecto a los profesores: horario de atención presencial, correo electrónico, teléfono despacho,...”, en el 75\% de los materiales analizados "Se propicia la interactividad entre estudiantes en la acción formativa", en el 70.8\% "Existen elementos visuales y/o audiovisuales en el curso que ofrecen una imagen del profesor", el 54.2\% "Posee un cronograma general de desarrollo de la actividad”. Por su parte con menos del 50\%, encontramos que en los materiales de los profesores participantes, en cuanto al diseño comunicativo se refiere, en el $45.8 \%$ de los materiales "Existe una planificación en las sesiones realizadas a través de herramientas de comunicación asincrónica", en el $41.7 \%$ "Existe una planificación en las sesiones realizadas a través de herramientas de comunicación sincrónica" y "Se utilizan diferentes tipos de lenguajes y sistemas simbólicos”, en el 29.2\% “Los alumnos pueden presentar sus

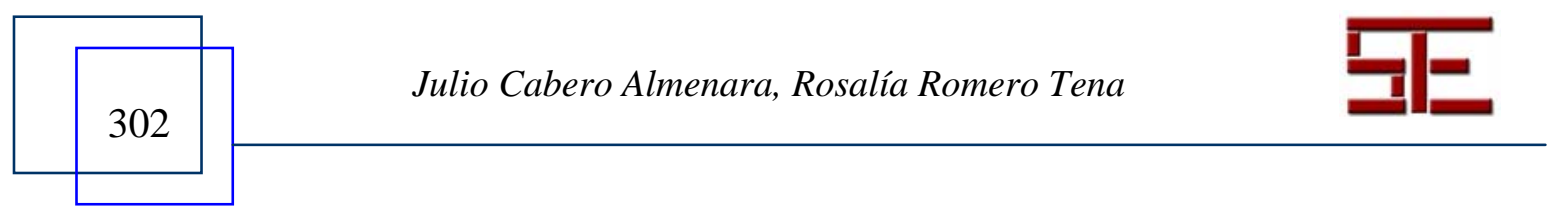




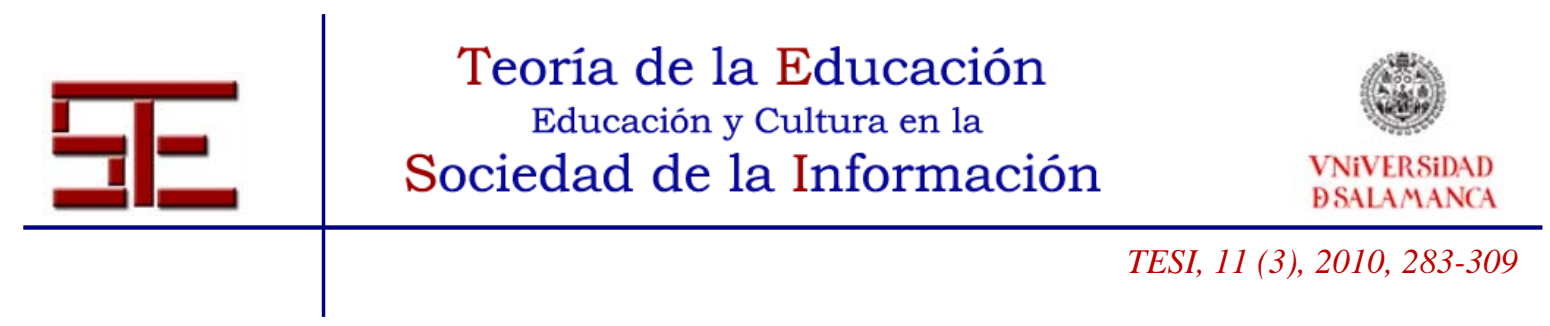

actividades en diferentes sistemas simbólicos", el 25\% "Posee un cronograma particular para el desarrollo de cada una de las partes de la actividad" y solo en el 20.8\% de los materiales "Se establece en las sesiones iniciales del curso un período para la sociabilización de los estudiantes”.

\section{5.- CONCLUSIONES.}

Uno de los aspectos que nos gustaría señalar es que los profesores que fueron considerados por sus compañeros de "buenas prácticas", suelen impartir más de una asignatura en la red. Dicho en otros términos tienen actitudes positivas para el desarrollo de estas acciones formativas. Así como también que suele ser una actividad a realizar de forma conjunta entre un grupo de profesores. Al mismo tiempo son profesores que suelen llevar más de dos años de impartición de acciones virtuales de enseñanza.

Señalar, curiosamente, que uno de los problemas que suele ser tenido en cuenta por los técnicos responsables de los servicios de e-learning de las Universidades, como es el de la plataforma, no es considerado sin embargo por los profesores, asumiendo que no es algo significativo para realizar una actividad de calidad.

Por lo que se refiere a los aspectos positivos que suelen percibir los profesores como más útiles de modalidad formativa, se destacan algunos: a) que a través de ella se puede poner a disposición de los estudiantes un fuerte volumen de materiales para su formación, y materiales que pueden ser ofrecidos en diferentes tipos de recursos, tanto textuales como audiovisuales y multimedias. En cierta medida podríamos decir que son profesores que perciben que las tecnologías de la información en general, y la telemática en particular pueden ser de gran ayuda para la formación de los estudiantes; b) el hecho de que los materiales pueden ser consultados por los estudiantes, en el momento que lo consideren oportuno; es decir, permite una flexibilización de la acción formativa. Aspecto este que repercute en que los estudiantes se puedan organizar de forma cómoda su actividad formativa, hecho que les lleva a los estudiantes a reconocer las posibilidades y ventajas que tiene este sistema; c) las posibilidades que esta modalidad formativa les permite poder comunicarse con los estudiantes, tanto de forma sincrónica como asincrónica; y d) facilita la individualización y el trato personal con los estudiantes a través de la tutoría virtual realizada a través de diferentes tipos de herramientas de comunicación, como el chat, el correo electrónico, los foros,...

Pero como es lógico suponer los profesores también nos señalaron una serie de aspectos negativos, entre los cuales destacaron el gran esfuerzo y de sobrecarga de trabajo que esta modalidad de formación le supone al profesor. Hecho que repercute en diferentes aspectos: inversión de tiempo para realizar materiales educativos de calidad y para estar actualizándolos constantemente, necesidad de estar constantemente

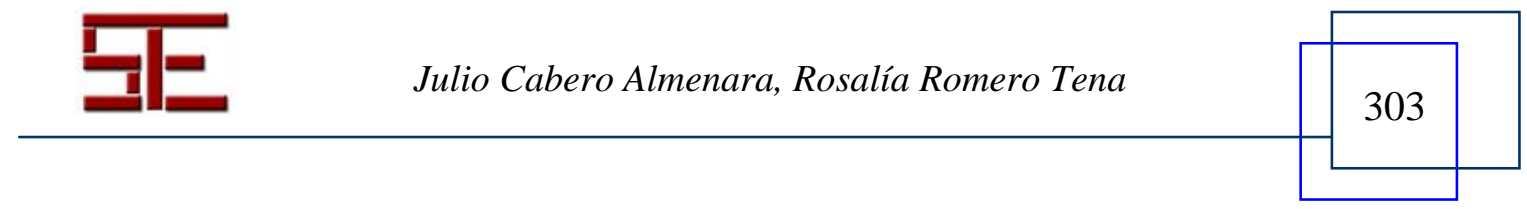




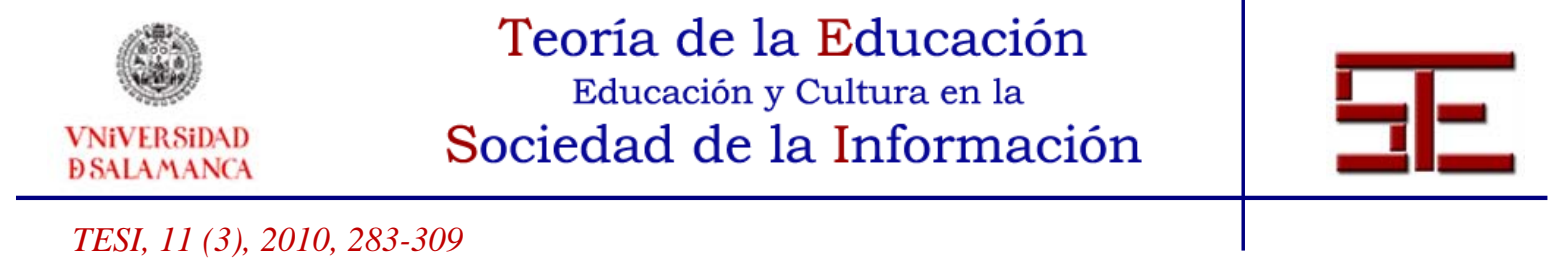

actualizado en el mundo de las tecnologías en general y de las posibilidades de la plataforma en particular, y de la atención constante que le requiere para responder a las demandas y solicitudes de los estudiantes.

Esta inversión de tiempo y esfuerzo, es más considerada por los profesores, cuando llegan a realizar la comparación entre la formación "Virtual" y "Presencial". La "virtual" se percibe como que requiere más demanda que la "presencial".

Al mismo tiempo algunos profesores llamaron la atención respecto al mal uso que se puede hacer de la formación virtual, y llegar a caer en el error de convertirla, como literalmente nos comentó uno en: "en una reprografía doméstica.” Si bien también, mostraron el problema que la tecnología tiene para algunos alumnos que la perciben como un elemento lúdico y no de formación, posiblemente por las experiencias que tengan de su uso doméstico.

Sí nos gustaría llamar la atención respecto a la percepción que han mostrado estos profesores de llegar a tener una verdadera formación del profesorado en este tema. Esta formación según algunos de ellos se ha visto demasiado sesgada hacia el componente tecnológico, cuando lo que necesitan y reclaman es una formación para la utilización didáctica y educativa del medio.

También es de señalar, cuando hemos preguntado a estos profesores la opinión que creían que sus compañeros tenían sobre la formación virtual, las respuestas iban en las siguientes direcciones: en primer lugar, que perciben que tiene ventajas, pero que también les suponen bastante esfuerzo, y coinciden con ellos en que la ven como no sustituta de la formación presencial. Aunque también los profesores mostraron cierto acuerdo respecto al desconocimiento que una gran mayoría tiene respecto a las posibilidades educativas de esta modalidad formativa.

Por otra parte, nuestros profesores, perciben que esta modalidad de enseñanza, no debe limitarse a su utilización como mero depositario de apuntes y documentos, sino como una herramienta para flexibilizar el proceso formativo de los estudiantes, realizar innovaciones educativas, y transformar los procesos de evaluación. En este último sentido es de señalar que llegan a utilizar una diversidad de técnicas y estrategias para determinar los aprendizajes alcanzados por los estudiantes; de todas formas los profesores reconocen que la gran mayoría combina la evaluación presencial con la evaluación a través de la plataforma. Pocos son los profesores que evalúan totalmente a los alumnos a través de los medios telemáticos.

Siguiendo con la evaluación nos gustaría destacar que los profesores perciben como verdaderamente útil las opciones de autoevaluación de los estudiantes que la plataforma posibilita.

Hemos encontrado un cierto acuerdo en nuestros profesores, al considerar que el número de alumnos que es aconsejable que formen parte de la experiencia deben ser

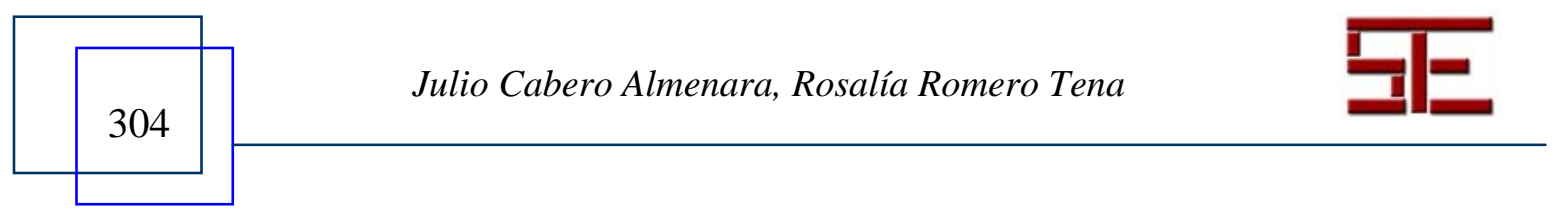




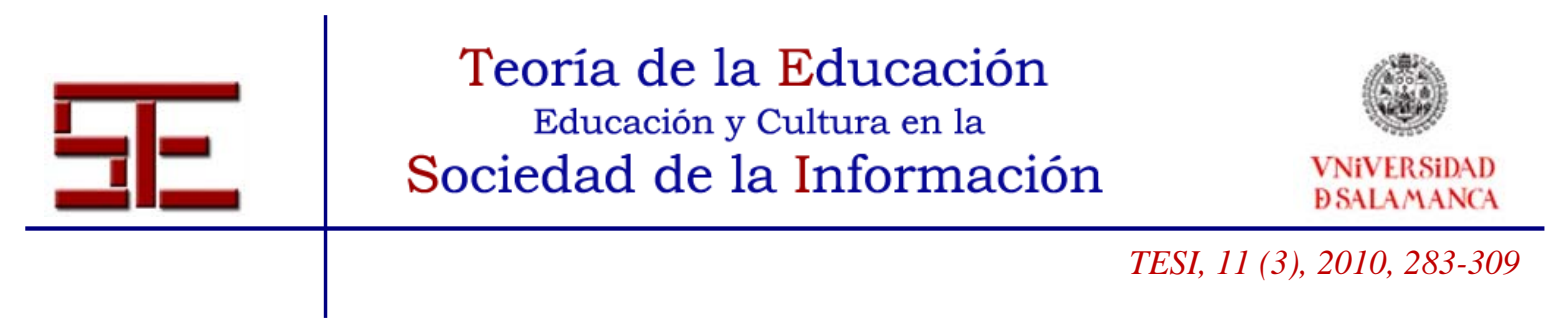

muy reducidos, en concreto la gran mayoría lo sitúa entre 10 y 25. Con más es muy complicado realizarla de forma correcta, teniendo en cuenta el esfuerzo de elaboración de materiales y de tutorización que requiere.

Otro acuerdo casi general entre nuestros profesores, es que perciben que su utilización ha tenido consecuencias significativas para el cambio del rendimiento de los estudiantes, puesto que los alumnos se implican, participan más y son más activos en la acción formativa.

Aunque nuestros profesores tienen experiencia en el diseño de materiales para la formación en red, la gran mayoría perciben como interesante y útil, que las Universidades creen servicios de apoyo. Servicios que en aquellas Universidades son ofrecidos, llegan a ser percibidos que funcionan bien.

En el aspecto técnico, tenemos que señalar que los profesores realizaron ciertas críticas a la plataforma utilizada en sus respectivas universidades: problemas de identificación de los estudiantes, dificultad para la creación de los grupos, el funcionamiento de los bancos de preguntas que poseen,...; pero de todas forma, las críticas no son mayoritarias y ni significativas. En cierta medida podríamos decir, que los profesores muestran un cierto acuerdo con su funcionamiento y posibilidades que ofrecen; y este acuerdo es independiente de la plataforma que utilicen, y que sea o propietaria o libre. En el caso de los estudiantes, las críticas se centraron en que algunas veces no funcionaba correctamente.

Por lo que se refiere a las competencias que deben tener los profesores para trabajar en esta modalidad formativa, los profesores perciben, que deben tener de dos tipos: técnicas y didácticas. En la primera sitúan fundamentalmente la del manejo de la plataforma y las herramientas que contiene, y en la segunda, incorporan una serie de cuestiones: diseño de contenidos, realización de entornos atractivos para los estudiantes, competencias comunicativas e interpersonales para favorecer la participación del alumnado, gestión del tiempo.

Dos han sido los procedimientos básicos que los profesores han utilizado para su capacitación: cursos realizados desde la propia Universidad y la autoformación. El segundo, hace que los profesores reclamen la necesidad de aumentar las acciones formativas por parte de la Universidad. Aunque también solicitan que las Universidad aumenten las dotaciones de medios y recursos, así como que realicen una atención personalizada y un reconocimiento a los profesores que se incorporen a esta modalidad formativa. Uno de los problemas que los profesores perciben es que al suponer más esfuerzo esta modalidad formativa que la presencial, y al no recibir reconocimientos específicos por parte de la Universidad, les lleva al desánimo y abandono.

Por lo que se refiere a la formación, el profesorado se muestra de acuerdo en que la misma no se limite a ellos, sino que también debe alcanzar al alumnado, que se llega a perder inicialmente en su manejo y desempeño.

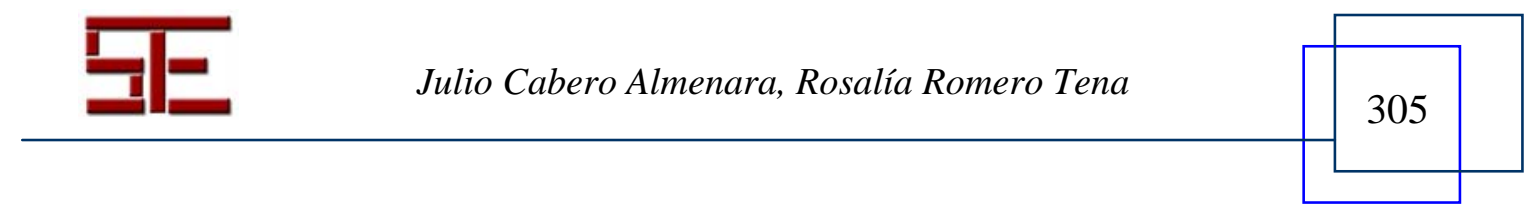




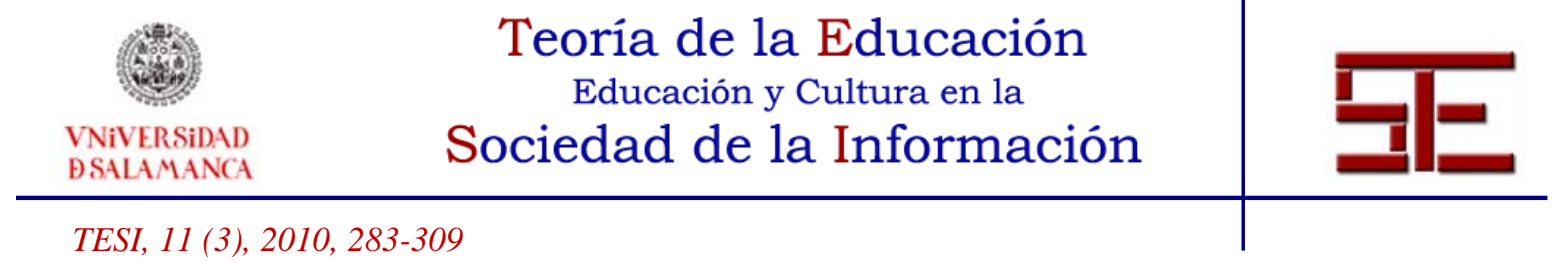

En este sentido de la capacitación de los alumnos, los profesores señalaban que éstos deberían de poseer las siguientes competencias para saber desenvolverse en la formación virtual y que superan el mero dominio tecnológico, que evidentemente reconocen que es necesario, y esto son: ser capaces de diseñar sus propias estrategias de aprendizaje, trabajar en equipo, competencias comunicativas interpersonales, y buscar información en la red.

Por lo que se refiere a los materiales utilizados por los profesores en la formación virtual, lo primero que tenemos que señalar es que en los tres dominios que recogía el instrumento utilizado: tecnológico, didáctico y comunicativo; las puntuaciones que se alcanzaron fueron bastante elevadas. En otros términos, podríamos considerar a los materiales como bien elaborados, con el manejo de una diversidad de recursos y de calidad.

Por lo que se refiere al diseño tecnológico, indicar que la gran mayoría de los cursos de los profesores presentaban elementos técnicos que permitían que los estudiantes siguieran el curso, incorporaban una diversidad de recursos que iban desde los textuales a los audiovisuales, multimedia y auditivos, los elementos audiovisuales intercalados estaban bien incorporados dentro del sistema, presentaban una correcta navegación y funcionaban correctamente todos los hiperenlaces, su manejo técnico era sencillo y no contenía problemas para desenvolverse para el estudiante, y se incorporan elementos que faciliten al estudiante la reflexión sobre las competencias tecnológicas que debe poseer el estudiante para el seguimiento de la acción formativa.

También tenemos que señalar que desde un punto de vista técnico-estético los materiales se encuentran claramente unificados: todas las páginas pueden ser identificadas a través de su título, existe uniformidad en los colores de los botones y elementos gráficos, y los botones de desplazamiento gráfico se encuentran ubicados siempre en las mismas posiciones.

Otro de los aspectos es que los cursos poseen mayoritariamente cronograma, disponen de un mapa de navegación, tablón de anuncios y permiten que los estudiantes puedan realizar trabajos grupales y colaborativos. Estas características no nos debían sorprender ya que la gran mayoría de las plataformas de teleformación, nos permiten realizar este tipo de cuestiones, independientemente de que sean libres o propietarias, como son las dos que mayoritariamente nos hemos encontrado.

Por lo que se refiere al diseño pedagógico, nos encontramos con materiales que son valorados como que presentan una estructura clara, que permiten la identificación de cada una de las partes del mismo, presentan una estructura similar en todo el curso que facilite su seguimiento por parte del estudiante, poseen una relación entre los objetivos, competencias y capacidades y los contenidos y actividades propuestos para la acción formativa.

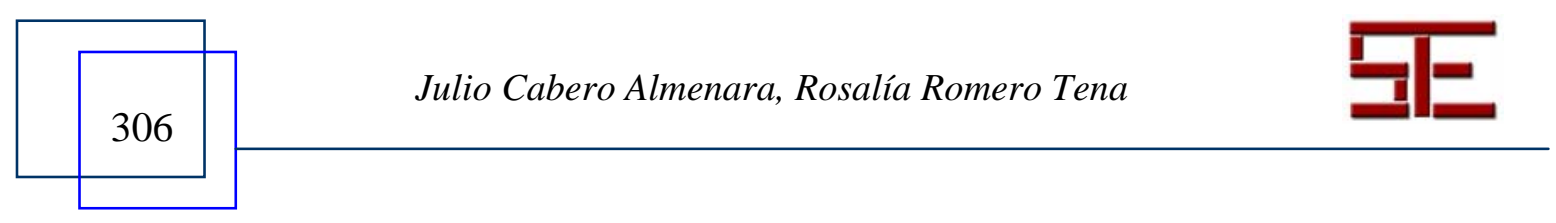




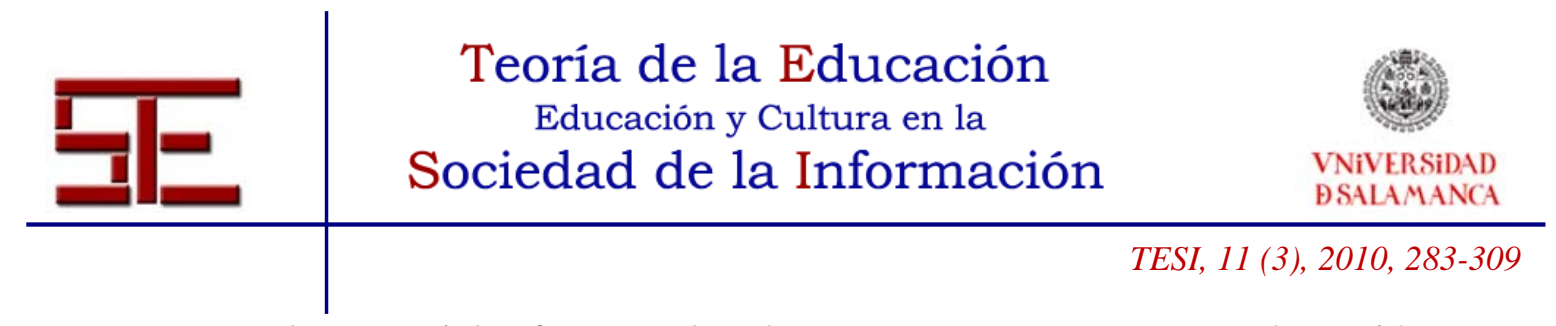

Por otra parte los materiales fueron valorados como que presentan una adecuación entre lo presentado en el curso, las actividades realizadas, y la modalidad de evaluación propuesta, poseen una coherencia entre los recursos didácticos y las estrategias metodológicas, presentan los objetivos que deben alcanzar los estudiantes, se observa una concordancia entre el volumen de contenidos y el tiempo asignado a la actividad formativa, y tienden a favorecer un aprendizaje activo en los estudiantes.

Es de señalar que los aspectos menores valorados hacían referencia a la existencia de referencia a las modalidades y formas de evaluación. Ello posiblemente se deba a que al estar los estudiantes inmersos en sistemas universitarios presenciales, la evaluación tiende a realizarse de forma presencial.

Por último, y en relación al diseño comunicativo de los materiales, lo primero a señalar es que los materiales fueron considerados como que su lenguaje estaba adaptado a las características de los estudiantes, se ofrece información y una imagen del profesor para su identificación por los alumnos, incorpora elementos para favorecer la interactividad, y se presenta un cronograma para el seguimiento del curso por parte del estudiante.

En definitiva podríamos decir que los materiales utilizados por los profesores se han elaborado con un verdadero cuidado, tanto en lo referido a lo técnico, como a lo didáctico y lo comunicativo.

\section{6.-BIBLIOGRAFÍA}

Arnal, J. y otros (1992). Investigación educativa, Barcelona: Labor.

Baelo, R. (2009). El e-learning una respuesta educativa a las demandas de la sociedad, Pixel-Bit. Revista de medios y Educación, 35, 87-96.

Bardin, L. (1977). Análisis de contenido, Madrid: Akal.

Bian, K. (2006). Lo que hacen los mejores profesores de Universidad, Valencia: Universitat de Valencia.

Blázquez, F. y Alonso, L. (2009). Funciones de profesores de e-learning, Pixel-Bit. Revista de medios y Educación, 34, 205-215.

Cabero, J. (dir) (2004). La red como instrumento de formación. Bases para el diseño de materiales didácticos, Píxel-Bit. Revista de Medios de Educación, 22, 5-23.

- (2008). Aportaciones al e-learning desde la investigación educativa, Sevilla: GID.

- (2010): Usos del e-learning en las Universidades Andaluzas: estado de la situación y análisis de buenas prácticas. Sevilla: GID.

Cabero, J. y López, E. (2009a). Evaluación de materiales multimedia en red en el Espacio Europeo de Educación Superior (EEES), Mataró: Da Vinci.

- $\quad$ (2009b). Construcción de un instrumento para la evaluación de las estrategias de enseñanza de cursos telemáticos de formación universitaria [artículo en línea],

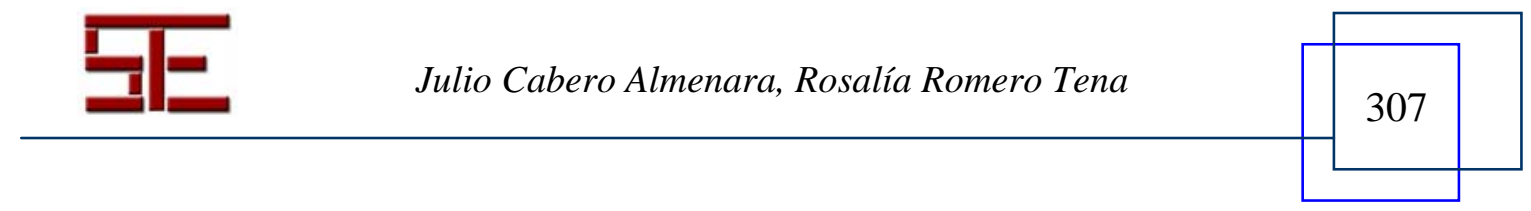




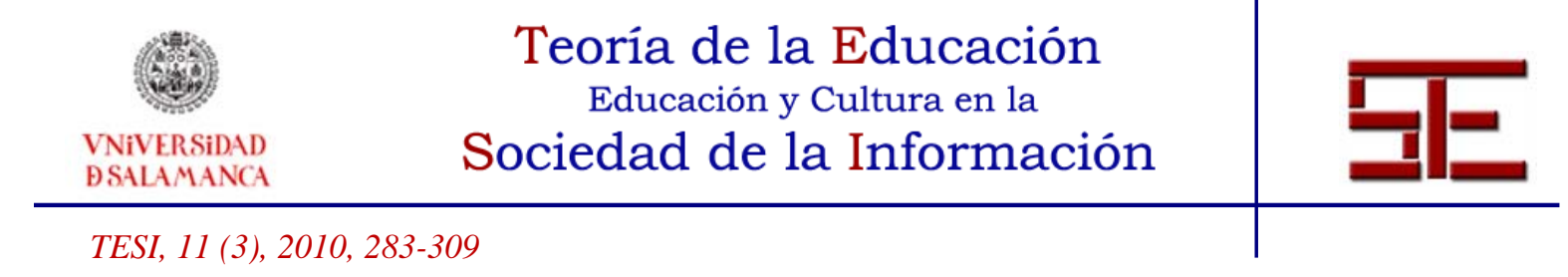

EDUTEC, Revista Electrónica de Tecnología Educativa. 28, http://edutec.rediris.es/revelec2/revelec28/ (10/9/2009).

Castañeda, L. y Sánchez, M. (2009). Entornos e-learning para la enseñanza superior: entre lo institucional y lo personalizado, Pixel-Bit. Revista de medios y Educación, 35, 175-163.

Clemente, M. y Santalla, Z. (1991). El documento persuasivo. Análisis de contenido y publicidad, Madrid: Ediciones Deusto.

Cohen, L. y Manion, L. (1990). Métodos de investigación educativa, Madrid: La Muralla.

Duart, J.M. y otros (2008). La Universidad en la sociedad red. Usos de Internet en Educación Superior, Barcelona: Ariel.

Epper, R. y Bates, A. (2004). Enseñar al profesorado cómo utilizar la tecnología. Buenas prácticas de instituciones líderes, Barcelona: UOC.

Gargllo, B. y otros (2003). La división digital en el proceso de integración de las NTIC en la educación. Diferencias de género entre alumnos de E.S.O. de la comunidad valenciana, Teoría de la Educación. Educación y Cultura en la Sociedad de la Información, 4, http://www3.usal.es/ teoriaeducacion/DEFAULT.HTM $(1 / 12 / 2003)$.

Hesse-Biber, S. y otros (1994). HyperRESEARCH from Researchware: A Content Analysis Tool for the Qualitative Researcher, Randolph, Research Ware, Inc.

Landaeta, A. (2007). Buenas prácticas de e-learning, Madrid: ANCED.

Llorente. M.C. y Cabero, J. (2008). La formación semipresencial a través de redes telemáticas (blended learning), Barcelona: DaVinci.

Macelo, C. y otros (2006). Propuesta de instrumentos para evaluar la calidad de la formación a través de Internet, en MARCELO, C. (cood): Prácticas de elearning, Granada: Octaedro, 228-242.

Means, B. y otros (2009). Evaluation of evidencie-based practices in online learning: A meta-analysis and review online learning studies, Washington, U.S. Department of Education.

Pérez Serrano, G. (1994). Investigación cualitativa. Madrid: La Muralla.

Planella, J. y Rodríguez, I. (2004). Del e-learning y sus otras miradas: una perspectiva social, Revista de Universidad y Sociedad del Conocimiento, 1, 1, http://www.uoc.edu/rusc/1/index.html (24/12/2004).

Pls Ramboll (2004). Studies in the context of the e-learning initiative: virtual models of European Universities (Lot1), PLS Ramboll, Denmark.

Stake, R.E. (1998). Investigación con estudios de casos, Madrid: Morata.

Tallent-Runnels, M.K. y otros (2006). Teaching courses online: a review of the research, Review of Educational Research, 76, 1, 93-135.

Tejada, J. y otros (2007). La didáctica en un entorno virtual interuniversitario: experimentación de ECTS apoyados en TIC, Pixel-Bit. Revista de medios y Educación, 32, 83-100.

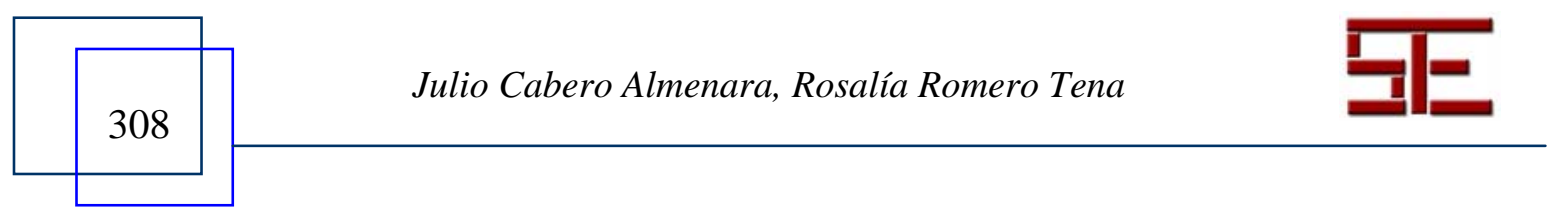




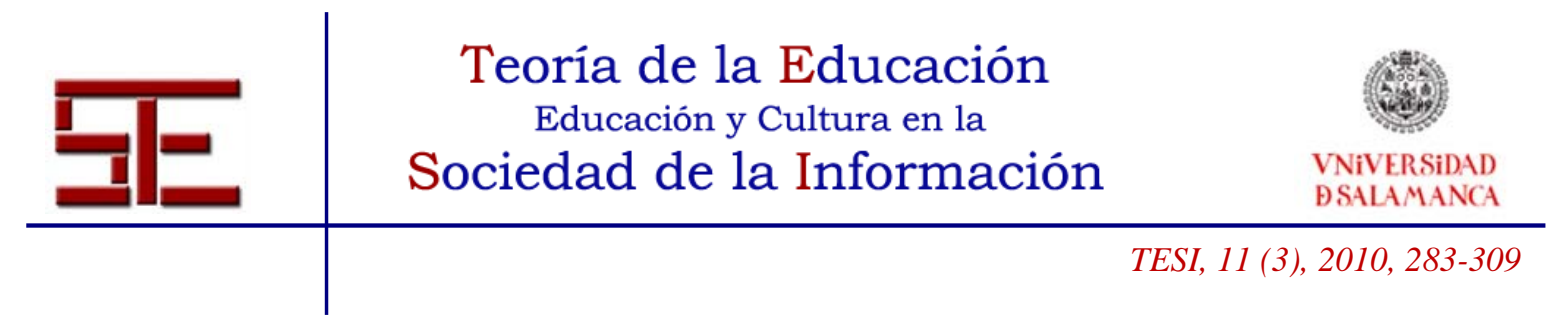

Nota:

1. La presente investigación forma parte del Proyecto de Excelencia PO7-SE-J.02670, denominado "Usos del e-learning en las Universidades Andaluzas: estado de la situación y análisis de buenas prácticas" dirigido por Julio Cabero y financiado por la Secretaría General de Universidades, Investigación y Tecnología de la Junta de Andalucía.

Para citar el presente artículo puede utilizar la siguiente referencia:

Cabero Almenara, J. y Romero Tena, R.: (2010). “Análisis de buenas prácticas del elearning en las universidades andaluzas". En De Pablos Pons, J. (Coord.) Buenas prácticas de enseñanza con TIC [monográfico en línea]. Revista Electrónica Teoría de la Educación: Educación y Cultura en la Sociedad de la Información. Vol. 11, n 1. Universidad de Salamanca, pp. 283-309. [Fecha de consulta: dd/mm/aaa].

http://revistatesi.usal.es/ revistas_trabajo/index.php/revistatesi/article/view/6293/6306 ISSN: 1138-9737

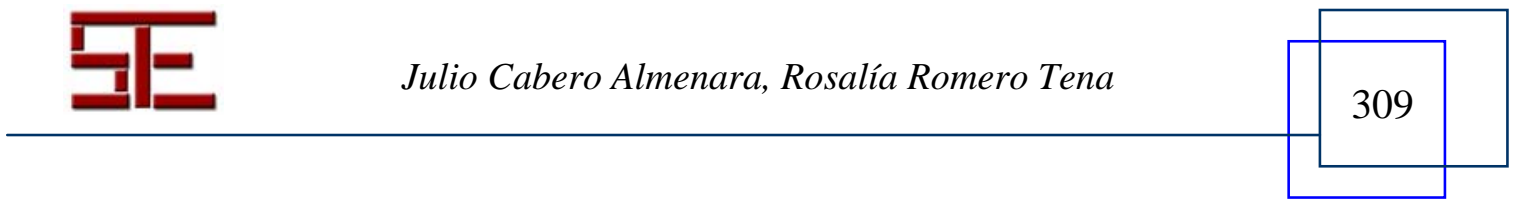

